\title{
Expansive Characteristics of Hydrated Limes and the Development of an Autoclave Test for Soundness
}

\author{
By Lansing S. Wells, Walter F. Clarke, and Ernest M. Levin
}

\begin{abstract}
A technique for preparing, curing, and autoclaving 1 - by 1 - by 10 -inch cement-lime bars was developed, and the expansive characteristics of 80 commercial hydrated limes were determined. On the basis of chemical analysis and percentage of unhydrated oxide, the hydrated limes were classified into four series: high-calcium, regularly hydrated dolomitic, highly hydrated dolomitic, and magnesian. Data on the expansions of cement-lime bars prepared in the proportions of 2 parts cement to 1 part lime, 1 part cement to 1 part lime, and 1 part cement to 2 parts lime, by weight, and autoclaved to 295 pounds per square inch gage pressure for 3 hours, showed that bars prepared with the regularly hydrated dolomitic limes, which had the highest percentages of unhydrated oxides, had the highest percentages of expansion. The high-calcium limes, characterized, in general, by the lowest percentages of unhydrated oxides, gave the lowest percentages of expansion. Most of the highly hydrated dolomitic limes had percentages of unhydrated oxide and expansion that were comparable to those of the high-calcium limes. An increase in the proportion of lime in the cement-lime bars was attended by an increase in expansion. The method for determining the linear expansion of cement-lime bars autoclaved at a steam-gage pressure of $295 \mathrm{lb} / \mathrm{in}^{2}$ (equivalent to a temperature of $216^{\circ} \mathrm{C}$.) was found to be reproducible, by three independent operators. The effect of 17 different portland cements on the expansion of cement-lime bars showed that the expansion values for a particular lime tended to increase as the expansion value of the constituent cement increased. Arbitrarily subtracting the expansion of the neat cement from the total expansion gave the most uniform result for the "net" expansion of the lime. With an autoclave specially modified for ascertaining the behavior of cement-lime bars during the course of autoclaving, it was found that only a slight amount of the total expansion occurred before a temperature of $150^{\circ} \mathrm{C}$. was reached, but above $150^{\circ}$ C. a rapid expansion rate was noted, which in turn tapered off before a temperature of $216^{\circ} \mathrm{C}$. was reached. Retarding the rate of heating resulted in a decrease in the total expansion. Finally, from criteria set forth for a procedure for determining the soundness of hydrated limes, a test is proposed with a suggested limit of expansion of 1.0 percent.
\end{abstract}

\section{Introduction}

It is highly important that a mortar or plaster, after being gaged with water and setting in place, shall not undergo appreciable change in volume. Since it was known that the hydration of the constituents of lime is attended by a marked increase in volume, a study was made at the National Bureau of Standards of the hydration of magnesia in dolomitic hydrated limes and put- ties [1]. ${ }^{1} \quad$ The publication of the paper soon led to consideration of the effect (if any) of unhydrated magnesia in partially hydrated dolomitic limes, and the Bureau became interested in this problem as it relates to plaster.

Extensive surveys showed that plaster failures characterized by the formation of bulges (large blisters) in the white coat, as illustrated in

\footnotetext{
1 Figures in brackets indicate the literature references at the end of this paper.
} 
figures 1 and 2, were widespread. Some of the salient features of the Bureau's findings were summarized recently [2] as follows:

"(1) Not a single instance has been found where bulging occurred in a white-coat plaster made with high-calcium lime; (2) ordinary dolomitic hydrated limes contain large amounts of unhydrated $\mathrm{MgO}$ and little or no free $\mathrm{CaO}$; (3) hydration of the free $\mathrm{MgO}$ to $\mathrm{Mg}(\mathrm{OH})_{2}$ is accompanied by marked expansion; and (4) after several years, the forces set up by this hydration and attendant expansion can and do cause the formation of bulges and the shearing of the white coat from the underlying coats." A more detailed paper is being prepared on this subject.

As a result of these studies, the Bureau was requested by other Government agencies to assist in formulating a specification that would exclude partially hydrated limes containing a high percentage of unhydrated oxides. Accordingly, the following tentative amendment to Federal Specification SS-L-351 for hydrated lime [3] was prepared: "The total free (unhydrated) calcium oxide $(\mathrm{CaO})$ and magnesium oxide $(\mathrm{MgO})$ in the hydrated product shall not exceed 8 percent by weight (calculated on the 'as received' basis)." A method was given for determining the quantity of unhydrated oxides.

Shortly thereafter certain of the manufacturers of regularly hydrated dolomitic lime started producing a more completely hydrated lime. In most instances this has been accomplished by installing autoclaves to hydrate the lime at elevated temperatures and pressures.

The 8-percent limit of the unhydrated oxide in hydrated limes recently has been included in specifications of the American Society for Testing Materials [4], as well as in those of the American Standards Association [5] for the hydrated lime to be used in white-coat plaster.

Nevertheless, a limitation on the percentage of unhydrated oxide has been criticized on the score that the quantity of unhydrated oxide itself may not be a complete indication of the inherent expansive characteristics of a hydrated lime. Such an objection would be obviated by a performance test. Since unsoundness usually does not exhibit itself for several years, a feasible performance test must also be an accelerated one.

Consequently, the purpose of the present investigation was to study more completely the ex-

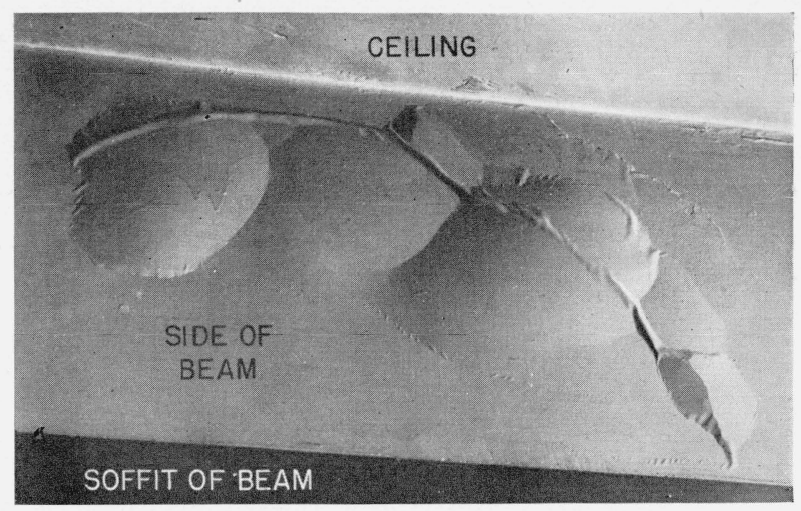

Figure 1. Bulges in white coat along the side of a concrete beam, caused by the expansion attending the slow hydration of free $\mathrm{MgO}$ present in the hydrated lime used in preparing the white coat.

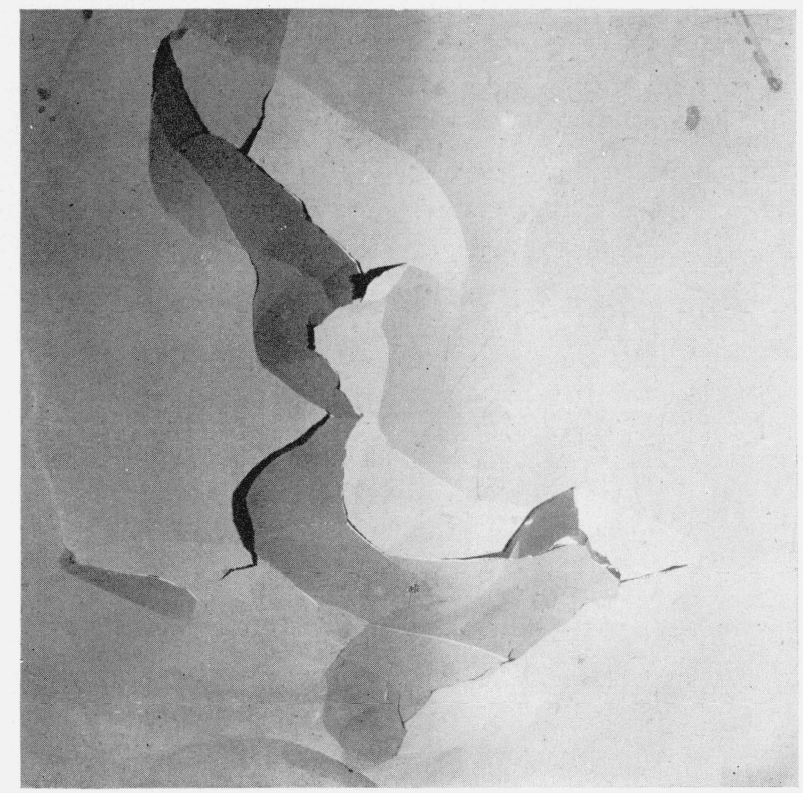

Figure 2. Bulging of white coat on a side wall, involving separation of the finish (or white) coat from the sanded gypsum base coat within an area of about $1 s q$ yd.

pansive characteristics of hydrated limes and to obtain data and information that might be used in formulating an accelerated performance test acceptable for a specification for the soundness of hydrated lime.

\section{Scope}

To procure a fair cross section of the structural hydrated limes being produced in the United States, 80 samples representing the different types were obtained from several widely separated lime-producing centers.

Because there is no satisfactory test procedure 
for ascertaining volume-change characteristics of hydrated limes alone, it is necessary to gage them with some cementitious material having hydraulic properties and then to determine the expansive properties of the resultant set mixture. After numerous experiments, portland cement was chosen as the most suitable gaging material.

It soon became evident that there were numerous factors that would have to be considered before the technique of testing cement-lime specimens could be developed. Among these were: The proportion of cement to hydrated lime, the preparation and curing of the specimens, and the procedure of autoclaving.

Since autoclaves and auxiliary apparatus for testing the soundness of portland cement [6] are already available in numerous testing laboratories throughout the United States, attention was directed toward developing a procedure for testing cement-lime specimens that would utilize this equipment.

Cement to lime mixtures proportioned $2: 1,1: 1$, and $1: 2$, by weight, and also a 1:1:5 cement, lime, sand mixture were tested. Studies were made of the relation of autoclave expansion values to the quantities of unhydrated oxides as determined by chemical analyses.

The reproducibility of the test results obtained by the use of the technique developed for the tests was obtained by comparing the values obtained by independent operators.

Autoclave tests were made of the effect of 17 different portland cements on the expansion characteristics of cement-lime mixtures.

A special apparatus was designed to measure the expansion of test specimens during the course of autoclaving, which facilitated studies of the effect of the rate of heating the autoclave to a given final temperature, the final temperature itself, and the duration of autoclaving.

On the basis of the techniques developed and the results obtained in this investigation, suggestions are made for a test procedure for determining the autoclave expansion of hydrated lime and the limits that appear applicable.

\section{Materials}

\section{Hydrated Limes}

Samples of the 80 representative hydrated limes, in bag quantities, were received directly from the manufacturers. Upon receipt, the materials were stored in airtight containers until used.

The chemical analyses were made in accordance with Federal Specification SS-L-351 for Hydrated Lime $[7,8]$, and the percentage of unhydrated oxide was calculated in accordance with Proposed Amendment 1 to this specification [3, 8]. The data are recorded in table 1 , columns 2 to 10 , inclusive.

On the basis of the chemical analyses, the hydrated limes were classified as high-calcium, dolomitic, and magnesian. Those containing less than 5 percent of total magnesia arbitrarily were classified as high-calcium, series A; those with more than 25 percent as dolomitic, series $\mathrm{B}$ and $\mathrm{C}$; and four limes, having between 5 and 25 percent of magnesia, as magnesian, series D. The hydrated dolomitic limes were further subdivided into "regularly hydrated," series B, where the major portion of the magnesia had been left unhydrated, and "highly hydrated," series C, where the major portion of the magnesia had been hydrated. The designation highly hydrated follows the terminology already used in a recent publication [9] and seems preferable to such terms as "autoclaved" or "pressure hydrated limes", since some of the new limes are produced by methods that do not involve steam pressures above atmospheric.

The hydrated limes in each series are arranged in table 1 by order of increasing percentage of calculated unhydrated oxides. With the exception of the highly hydrated limes $67,68,71,74,75$, and 76 , which were experimentally produced, all of the hydrated limes were commercially available.

The subdivision of the hydrated limes into series A, B, C, and D and the arrangement in each series by order of increasing percentage of unhydrated oxides will be maintained in subsequent tables and figures.

No distinction between "mason's" and "finishing" hydrated limes is being made in this investigation, because the kind of unsoundness characterized by an over-all increase in volume is of concern whether a lime is to be used in a mortar or in a plaster. ${ }^{2}$

\footnotetext{
${ }^{2}$ It should be emphasized that this kind of unsoundness is not to be confused with the kind resulting in the formation of small crater-like holes known
} as "pits" or "pops", which sometimes occur on plastered surfaces. 
TABLE 1. Chemical analysis and calculated percentage of unhydrated oxides for 80 hydrated limes, together with the percentages of linear expansion of cement-lime bars prepared with these limes in the proportion of 2 cement:1 lime; 1 cement:1 lime; and 1 cement:2 lime, by weight, and subsequently autcclaved at a steam-gage pressure of $295 \mathrm{lb} / \mathrm{in} .^{2}$ for $3 \mathrm{hr}$

[The specimens were all prepared with cement 10, which, without the addition of hydrated lime, had a linear expansion of 0.11 percent]

\begin{tabular}{|c|c|c|c|c|c|c|c|c|c|c|c|c|}
\hline \multirow{2}{*}{$\begin{array}{l}\text { Lime } \\
\text { number }\end{array}$} & \multicolumn{8}{|c|}{ Chemical analysis (oxide composition) } & \multirow{2}{*}{$\begin{array}{l}\text { Calcu- } \\
\text { lated un- } \\
\text { hydrated } \\
\text { oxides }\end{array}$} & \multicolumn{3}{|c|}{$\begin{array}{l}\text { Linear expansion cement-lime } \\
\text { bars in the proportion: }\end{array}$} \\
\hline & $\begin{array}{l}\text { Free } \\
\mathrm{H}_{2} \mathrm{O}\end{array}$ & $\begin{array}{l}\text { Com- } \\
\text { bined } \\
\mathrm{H}_{2} \mathrm{O}\end{array}$ & $\mathrm{CO}_{2}$ & $\mathrm{SiO}_{2}$ & $\mathrm{R}_{2} \mathrm{O}_{3}$ & $\mathrm{CaO}$ & $\mathrm{MgO}$ & Total & & $2 \mathrm{C}: 1 \mathrm{~L}$ & $1 \mathrm{C}: 1 \mathrm{~L}$ & $1 \mathrm{C}: 2 \mathrm{~L}$ \\
\hline 1 & 2 & 3 & 4 & 5 & 6 & 7 & 8 & 9 & 10 & 11 & 12 & 13 \\
\hline
\end{tabular}

SERIES A-HIGH-CALCIUM HYDRATED LIMES

\begin{tabular}{|c|c|c|c|c|c|c|c|c|c|c|c|c|}
\hline & $\%$ & $\%$ & $\%$ & $\%$ & $\%$ & $\%$ & $\%$ & $\%$ & $\%$ & $\%$ & $\%$ & $\%$ \\
\hline 1 & 0.57 & 23.74 & 0.51 & 0.54 & 0.20 & 73.92 & 0.46 & 99.94 & 0.0 & 0.13 & 0.18 & 1.1 \\
\hline 2 & .41 & 23.18 & 1. 58 & .58 & .38 & 72.82 & .67 & 99.62 & .0 & .12 & .19 & 1.1 \\
\hline 3 & .24 & 23.59 & 1.02 & .44 & .32 & 73.97 & .33 & 99.91 & .0 & .12 & .16 & 0.71 \\
\hline 4 & .36 & 23.68 & 0.56 & .60 & .42 & 73.90 & .35 & 99.87 & .0 & .12 & .15 & .56 \\
\hline 5 & .29 & 23.90 & .39 & .50 & .30 & 73.62 & .82 & 99.82 & .0 & .10 & .13 & .24 \\
\hline 6 & .66 & 23.42 & .99 & .56 & .14 & 73.17 & .60 & 99.54 & .0 & .12 & .20 & 1.4 \\
\hline 7 & .59 & 23.66 & .70 & .16 & .55 & 73.65 & .69 & 100.00 & .1 & .14 & .18 & 1.0 \\
\hline 8 & .83 & 23.26 & 1.10 & .20 & .55 & 73.47 & .72 & 100.13 & .5 & .14 & .19 & 0.90 \\
\hline 9 & .54 & 23.26 & 0.68 & .86 & .48 & 73.31 & .81 & 99.94 & .8 & .14 & .21 & .86 \\
\hline 10 & .54 & 22.96 & 1. 56 & .42 & $: 24$ & 73. 22 & .96 & 99.90 & .8 & .16 & .21 & .69 \\
\hline 11 & .53 & 23.06 & 0.70 & .74 & .60 & 72.60 & 1.04 & 99. 27 & 1.0 & .14 & .19 & 1.5 \\
\hline 12 & .29 & 23.00 & .97 & .80 & .50 & 73.29 & 0.61 & 99.46 & 1.1 & .13 & .19 & 1.3 \\
\hline 13 & .75 & 22.95 & .67 & 1.14 & .78 & 71.35 & 1.82 & 99.46 & 1.1 & .13 & .20 & 0.78 \\
\hline 14 & .68 & 22.58 & 1. 27 & 1.02 & .64 & 71.89 & 1.19 & 99. 27 & 1. 2 & .13 & 18 & .59 \\
\hline 15 & .44 & 23.07 & 0.33 & 1.09 & .50 & 72.78 & 1.06 & 99.27 & 1.6 & .12 & .18 & .97 \\
\hline 16 & .34 & 22.88 & 1. 19 & 0.58 & .38 & 73.00 & 1.41 & 99. 78 & 1.7 & .16 & .23 & 1.0 \\
\hline 17 & .58 & 22.99 & 0.65 & 1.00 & .46 & 71.55 & 2. 41 & 99.64 & 1.8 & .17 & .35 & 2.0 \\
\hline 18 & .30 & 23. 23 & .27 & 0.70 & .46 & 73.68 & 1. 18 & 99.82 & 2. 2 & .16 & .25 & 1.3 \\
\hline 19 & .40 & 22.20 & 1.37 & 1.88 & .92 & 72.02 & 1.09 & 99.88 & 2.3 & .13 & .24 & 1. 2 \\
\hline 20 & .33 & 22.48 & 0.87 & 0.86 & .16 & 71.23 & 3. 02 & 98.95 & 3. 2 & .19 & .52 & 4.1 \\
\hline 21 & .70 & 22.01 & 1. 01 & 1. 31 & .76 & 72.42 & 1. 29 & 99.50 & 3.9 & .17 & .24 & 1.8 \\
\hline
\end{tabular}

SERIES B-REGULARLY HYDRATED DOLOMITIC LIMES

\begin{tabular}{|c|c|c|c|c|c|c|c|c|c|c|c|c|}
\hline 22 & 0.36 & 20.70 & 0.99 & 1. 26 & 0.66 & 44.81 & 31. 12 & 99.90 & 16.1 & 2.5 & 8.5 & - . . . \\
\hline 23 & .19 & 18. 21 & 1. 64 & 1. 75 & 1.07 & 45.17 & 31.83 & 99.86 & 22.1 & 7.8 & 16.5 & -..... \\
\hline 24 & .25 & 17.51 & 2. 57 & 0.82 & 0.36 & 52.58 & 25. 79 & 99.88 & 22.1 & 3.3 & 9.9 & ...... \\
\hline 25 & .30 & 19.03 & 0.45 & 1.04 & .48 & 46.14 & 32.54 & 99.98 & 22.7 & 2.0 & 7.6 & - . \\
\hline 26 & .35 & 18.21 & 1.32 & 1.20 & .44 & 47.51 & 30.64 & 99.67 & 22.9 & 1.3 & 4. 6 & - \\
\hline 27 & .30 & 17. 96 & 0.63 & 0.94 & .36 & 46.72 & 33.08 & 99.99 & 25.9 & 4.1 & 10.0 & 12. 7 \\
\hline 28 & .13 & 17.90 & 1.01 & .12 & .16 & 47.41 & 33.09 & 99.82 & 26.2 & 7.2 & 12.9 & 14.4 \\
\hline 29 & .28 & 16. 63 & 3.13 & .20 & .18 & 46.98 & 32.51 & 99.91 & 26.2 & 4. 6 & 9.2 & 13. 1 \\
\hline 30 & .28 & 17.58 & 1.18 & .28 & .22 & 47.58 & 32.62 & 99.74 & 26.4 & 4.0 & 8.3 & 12.0 \\
\hline 31 & .22 & 17.41 & 1. 73 & .14 & .14 & 47.00 & 33.30 & 99.94 & 26.5 & 4.5 & 10.5 & ..... \\
\hline 32 & .15 & 16. 63 & 2. 79 & .26 & .16 & 46.81 & 32.93 & 99. 73 & 26.8 & 6.3 & 11.8 & 13.6 \\
\hline 33 & .29 & 16. 99 & 1.45 & .34 & .30 & 47.21 & 32.51 & 99.09 & 27.1 & 5.7 & 17.3 & - \\
\hline 34 & .20 & 17.01 & 1. 79 & .40 & .28 & 47.06 & 33. 24 & 99.98 & 27.4 & 4.0 & 10.0 & 15.6 \\
\hline 35 & .20 & 17. 26 & 0.88 & .34 & .22 & 47.43 & 32.98 & 99.31 & 27.7 & 10.5 & 16.4 & 16.5 \\
\hline 36 & .19 & 17. 25 & .50 & .54 & .48 & 47.29 & 33.53 & 99.78 & 28.5 & 9.3 & 16.9 & - \\
\hline 37 & .24 & 16. 94 & .94 & .20 & .18 & 47.43 & 33.97 & 99.90 & 29.3 & 2.6 & 7.1 & 10.6 \\
\hline 38 & .04 & 16. 56 & .98 & .20 & .10 & 48.43 & 32.98 & 99. 29 & 29.9 & 12.6 & 17.7 & - \\
\hline 39 & .21 & 15. 96 & 2. 09 & .14 & .10 & 47.76 & 33. 69 & 99.95 & 30.4 & 6.8 & 11.7 & -.... \\
\hline 40 & .17 & 16. 65 & 0.90 & .20 & .12 & 47.83 & 34.10 & 99.97 & 30.4 & 11.0 & 13.8 & 14.5 \\
\hline 41 & .23 & 16. 53 & 1. 02 & .24 & .12 & 47.79 & 34.06 & 99.99 & 30.5 & 10.4 & 13.5 & 14. 2 \\
\hline 42 & .16 & 15.97 & 1. 59 & .37 & .53 & 48.45 & 33.05 & 100.12 & 30.7 & 5.1 & 12.7 & -.... \\
\hline 43 & .20 & 16. 29 & 1.31 & .18 & .16 & 47.85 & 34.01 & 100.00 & 30.8 & 6.6 & 12. 2 & 13.6 \\
\hline 44 & .22 & 16. 28 & 0.75 & .80 & .54 & 47. 63 & 33.63 & 99.85 & 30.8 & 8.0 & 15.8 & 17.9 \\
\hline 45 & .43 & 15.81 & 1. 45 & .10 & .12 & 46.78 & 35.21 & 99.90 & 32.1 & 4.0 & 9.9 & 10.7 \\
\hline 46 & .04 & 15. 91 & 1.05 & .14 & .18 & 48.32 & 34.30 & 99.94 & 32.5 & 11.7 & 17.8 & - . \\
\hline 47 & .30 & 15.45 & 0.79 & 1.42 & .46 & 47.70 & 33.82 & 99.94 & 32.8 & 6.5 & 14.1 & - \\
\hline 48 & .50 & 14. 58 & 1. 25 & 1.34 & .68 & 48. 27 & 33.00 & 99.52 & 34.3 & 8.1 & 17.8 & - . \\
\hline
\end{tabular}


TABLE 1. Chemical analysis and calculated percentage of unhydrated oxides for 80 hydrated limes, together with the percentages of linear expansion of cement-lime bars prepared with these limes in the proportion of 2 cement:1 lime; 1 cement:1 lime; and 1 cement:2 lime, by weight, and subsequently autoclaved at a steam-gage pressure of $295 \mathrm{lb} / \mathrm{in} .^{2}$ for $3 \mathrm{hr}-\mathrm{Continued}$

[The specimens were all prepared with cement 10, which, without the addition of hydrated lime, had a linear expansion of 0.11 percent]

\begin{tabular}{|c|c|c|c|c|c|c|c|c|c|c|c|c|}
\hline \multirow{2}{*}{$\begin{array}{l}\text { Lime } \\
\text { number }\end{array}$} & \multicolumn{8}{|c|}{ Chemical analysis (oxide composition) } & \multirow{2}{*}{$\begin{array}{l}\text { Calcu- } \\
\text { lated un- } \\
\text { hydrated } \\
\text { oxides }\end{array}$} & \multicolumn{3}{|c|}{$\begin{array}{l}\text { Linear expansion cement-lime } \\
\text { bars in the proportion: }\end{array}$} \\
\hline & $\begin{array}{l}\text { Free } \\
\mathrm{H}_{2} \mathrm{O}\end{array}$ & $\begin{array}{l}\text { Com- } \\
\text { bined } \\
\mathrm{H}_{2} \mathrm{O}\end{array}$ & $\mathrm{CO}_{2}$ & $\mathrm{SiO}_{2}$ & $\mathrm{R}_{2} \mathrm{O}_{3}$ & $\mathrm{CaO}$ & $\mathrm{MgO}$ & Total & & $2 \mathrm{C}: 1 \mathrm{~L}$ & $1 \mathrm{C}: 1 \mathrm{~L}$ & $1 \mathrm{C}: 2 \mathrm{~L}$ \\
\hline 1 & 2 & 3 & 4 & 5 & 6 & 7 & 8 & 9 & 10 & 11 & 12 & 13 \\
\hline
\end{tabular}

SERIES C-HIGHLY HYDRATED DOLOMITIC LIMES

\begin{tabular}{|c|c|c|c|c|c|c|c|c|c|c|c|c|}
\hline & $\%$ & $\%$ & $\%$ & $\%$ & $\%$ & $\%$ & $\%$ & $\%$ & $\%$ & $\%$ & $\%$ & $\%$ \\
\hline 49 & 0.04 & 25.41 & 1. 44 & 1.06 & 0.52 & 41.87 & 29.45 & 99.79 & 1.4 & 0.18 & 0.25 & 0.85 \\
\hline 50 & .21 & 25. 28 & 1. 72 & 0.24 & .18 & 42.58 & 29.75 & 99.96 & 2. 2 & .21 & .30 & ...... \\
\hline 51 & .16 & 25.52 & 1.32 & .23 & .35 & 43. 01 & 29.65 & 100. 24 & 2.3 & .26 & .42 & 3.1 \\
\hline 52 & .00 & 25.41 & 1. 33 & .26 & .36 & 42.47 & 29.88 & 99.71 & 2.3 & .21 & .31 & 1.3 \\
\hline 53 & .51 & 24.56 & 1.87 & 1. 56 & .50 & 41.83 & 29.09 & 99.92 & 2. 6 & .26 & 1.1 & 5.8 \\
\hline 54 & .04 & 25.31 & 1. 56 & 0.18 & .18 & 42.59 & 30.08 & 99.94 & 2. 6 & .22 & 0.36 & 2. 2 \\
\hline 55 & .16 & 25.15 & 1.36 & .20 & .20 & 42. 70 & 29.57 & 99.34 & 2. 7 & .23 & .48 & 1.9 \\
\hline 56 & .24 & 25. 22 & 0.66 & 1. 66 & .56 & 41.99 & 29.71 & 100.04 & 2. 9 & .21 & .29 & 1.9 \\
\hline 57 & .09 & 25.14 & 1. 75 & 0.26 & .10 & 42.68 & 30.04 & 100.06 & 2. 9 & .25 & .37 & 2.1 \\
\hline 58 & .02 & 24.77 & 1. 16 & 1.98 & .70 & 42.06 & 29.23 & 99.92 & 3.0 & .25 & .33 & 1.4 \\
\hline 59 & .17 & 24.47 & 2. 79 & 0.18 & .14 & 42.49 & 29.75 & 99.99 & 3.0 & .24 & .36 & 2.0 \\
\hline 60 & .17 & 24.87 & 1. 12 & 1. 53 & .62 & 41.95 & 29.68 & 99.94 & 3.2 & .24 & .50 & 2.5 \\
\hline 61 & .23 & 24.58 & 1. 98 & 0.18 & .16 & 42.91 & 29.14 & 99.18 & 3.2 & .22 & .31 & 0.95 \\
\hline 62 & .25 & 24.37 & 2. 00 & 1.45 & .62 & 42.10 & 29.46 & 100.25 & 3.4 & .22 & .40 & 3.3 \\
\hline 63 & .17 & 25.18 & 0.37 & 1.82 & .44 & 42. 12 & 29.82 & 99.92 & 3.4 & .22 & .36 & ..... \\
\hline 64 & .09 & 25.67 & .38 & 0.14 & .08 & 43.22 & 30.17 & 99.75 & 3.5 & .24 & .50 & 3.6 \\
\hline 65 & .19 & 23.66 & 3. 12 & .16 & .20 & 42. 78 & 29.09 & 99.20 & 4.0 & .22 & .31 & 0.65 \\
\hline 66 & .08 & 24.82 & 0.87 & .02 & .19 & 43.41 & 30.24 & 99.63 & 5.1 & .34 & 1. 2 & 5.6 \\
\hline 67 & .16 & 23.59 & 2. 30 & 1. 28 & .48 & 42.37 & 29.58 & 99.76 & 5. 2 & .41 & 2. 6 & 9.0 \\
\hline 68 & .14 & 22.40 & 3.31 & 1. 64 & .64 & 42.13 & 29.43 & 99.69 & 6.6 & .38 & 2.4 & 8.4 \\
\hline 69 & .09 & 22.72 & 3. 40 & 0.22 & .16 & 42. 89 & 29.93 & 99.41 & 6.8 & .73 & 5.1 & 8.9 \\
\hline 70 & .20 & 23.35 & 1.18 & 2.18 & .89 & 42.89 & 29.43 & 100.12 & 6.9 & .88 & 7.1 & 11.2 \\
\hline 71 & .07 & 22.41 & 3. 75 & 0.14 & .30 & 43.02 & 30.18 & 99.87 & 7.5 & .54 & 5.2 & ...... \\
\hline 72 & .13 & 23.83 & 1.06 & .20 & .12 & 43. 73 & 30.58 & 99.65 & 7.7 & .63 & 3.3 & 8.5 \\
\hline 73 & .09 & 23.58 & 0.91 & .14 & .26 & 44.15 & 30.84 & 99.97 & 9.0 & .82 & 5. 6 . & 9.1 \\
\hline$a 745$ & .30 & 20.20 & 2. 83 & 4. 48 & .76 & 41. 66 & 29.40 & 99.63 & 11. 6 & .48 & 2.8 & 8.8 \\
\hline \multirow[t]{2}{*}{ a 776} & .28 & 20.65 & 2. 64 & 3.44 & .72 & 42.30 & 29.91 & 99.94 & 11.7 & .55 & 3.2 & 8.3 \\
\hline & .15 & 20.98 & 3.35 & 0.28 & .20 & 44.03 & 30.97 & 99.96 & i2. 6 & 1.7 & 7.1 & 8. 2 \\
\hline
\end{tabular}

SERIES D-MAGNESIAN HYDRATED LIMES

\begin{tabular}{|c|c|c|c|c|c|c|c|c|c|c|c|c|}
\hline 77 & 0.38 & 21.67 & 0.67 & 2. 26 & 0.82 & 67.78 & 6.24 & 99.82 & 5. 9 & 0.19 & 0.50 & 3. 6 \\
\hline 78 & .39 & 21.92 & .96 & 0.76 & .78 & 62.96 & 11.88 & 99.65 & 7. 2 & .22 & .39 & 1. 1 \\
\hline a 79 & .99 & 17.69 & 4. 95 & 2.47 & 3. 13 & 64.61 & 6.25 & 100.00 & 9.8 & .22 & .54 & 4. 6 \\
\hline a80 & .52 & 19. 79 & 1.10 & 2. 64 & 1. 30 & 57.13 & 16.88 & 99.36 & 12. 7 & .28 & .70 & 3. 8 \\
\hline
\end{tabular}

a Failed to meet the requirement of Federal Specification SS-L-351 that the total CaO plus MgO shall be not less than $95 \%$, calculated on nonvolatile basis. 


\section{Cements}

Seventeen brands of portland cement were used in the investigation. The cements conformed to Federal Specification SS-C-192, Type 1 [10].

The autoclave expansions of the cements alone were determined in accordance with a test that had been adopted as standard [6] and are listed in table 2.

TABLE 2. Autoclave expansion of 1-by 1-by 10-in. neat specimens of portland cement for determination of soundness of portland cement 1

\begin{tabular}{|c|c|c|c|c|c|}
\hline $\begin{array}{l}\text { Cement } \\
\text { number }\end{array}$ & $\begin{array}{l}\text { Linear ex- } \\
\text { pansion }\end{array}$ & $\begin{array}{l}\text { Cement } \\
\text { number }\end{array}$ & $\begin{array}{c}\text { Linear ex- } \\
\text { pansion }\end{array}$ & $\begin{array}{l}\text { Cement } \\
\text { number }\end{array}$ & $\begin{array}{c}\text { Linear ex } \\
\text { pansion }\end{array}$ \\
\hline & $\%$ & & $\%$ & & $\%$ \\
\hline 1 & 0.00 & 7 & 0.06 & 13 & 0.18 \\
\hline 2 & .01 & 8 & .07 & 14 & .19 \\
\hline 3 & .02 & 9 & .11 & 15 & .23 \\
\hline 4 & .04 & 10 & .11 & 16 & .27 \\
\hline 5 & .04 & 11 & .11 & 17 & .30 \\
\hline 6 & .04 & 12 & .17 & & \\
\hline
\end{tabular}

1 Standard method of test for autoclave expansion of portland cement ASTM Designation: C151-43, ASTM Standards, part II, 14 (1946); also American Association State Highway Officials Standard AASHO No. T107-45; as well as Federal Specification SS-C-158b-46 for Cement, Hydraulic; General Specifications (methods for sampling, inspection, and testing) [6].

\section{Sand}

The sand used in the preliminary tests on cement-lime-sand mortars was natural silica sand from Ottawa, Ill., graded to pass a No. 20 sieve and be retained on a No. 30 sieve. It conformed to Federal Specification SS-C-158b, paragraph $\mathrm{F}-51[11]$.

\section{Preparation and Curing of Test Specimens}

All mixtures were prepared and all tests were performed in a laboratory in which the temperature was maintained at $21^{\circ} \pm 1^{\circ} \mathrm{C}\left(70^{\circ} \pm 2^{\circ} \mathrm{F}\right)$, and the relative humidity at $55 \pm 5$ percent. The atmosphere of the moist closet was maintained at the same temperature as the laboratory and at a relative humidity of $95 \pm 3$ percent.

The cement-lime test specimens, in the several series of tests, were proportioned by dry weight, namely, $300 \mathrm{~g}$ of cement to $300 \mathrm{~g}$ of lime, $200 \mathrm{~g}$ of cement to $400 \mathrm{~g}$ of lime, and $500 \mathrm{~g}$ of cement to $250 \mathrm{~g}$ of lime; hereafter designated as $1 \mathrm{C}: 1 \mathrm{~L}$, $1 \mathrm{C}: 2 \mathrm{~L}$, and $2 \mathrm{C}: 1 \mathrm{~L}$, respectively. A limited number of mortar specimens was proportioned by dry weight in the ratio of $150 \mathrm{~g}$ of cement to $150 \mathrm{~g}$ of lime to $750 \mathrm{~g}$ of sand; hereafter designated as $1 \mathrm{C}: 1 \mathrm{~L}: 5 \mathrm{~S}$. These quantities in each case were sufficient for the preparation of two test specimens.

To prepare cement-lime bars suitable for autoclaving, it was found necessary to modify the method used for making portland cement bars as given in Federal Specification SS-C-158b.

In the preparation of the cement-lime bars, the weighed amounts of cement and lime were shaken vigorously in a 2 -qt jar until the mixture appeared uniform. The dry mix was spread on a smooth, nonabsorbent, noncorrosive plate and trowelled until visible agglomerates of lime were dispersed. Then, after collection of the material into a truncated cone, an inner and outer crater were formed in the dry mix with the end of the handle of a trowel.

For the remainder of the operation, the hands were protected with rubber gloves. During an interval of $2 \mathrm{~min}$, (1) a measured quantity of clean water (temperature $21^{\circ} \pm 1.7^{\circ} \mathrm{C}$ ) was added; (2) the dry material was folded over the exposed surface of the water; and (3) the dry material was cut into the water with the edge of a trowel. The mix was worked by kneading, squeezing, and pounding for an additional period of $3 \mathrm{~min}$. The mass was then allowed to stand undisturbed for $1 \mathrm{~min}$ and finally vigorously reworked for $1 \mathrm{~min}$.

The above procedure was found necessary because of the difficulty in wetting cement-lime mixes and the tendency on the part of the operator to add excessive quantities of mixing water to most cement-lime mixes. By following these modifications, many mixes that at first appeared too dry eventually acquired the desired consistency by the vigorous working. The advantages of this procedure were twofold: (1) The quantity of mixing water could be reduced, and consequently the breakage of the bars resulting from shrinkage during curing was almost wholly eliminated, and (2) the quantity of water required by different limes of the same type was, with few exceptions, reduced to a narrow range.

Following completion of mixing, the Vicat penetration was determined according to the procedure given in Federal Specification SS-C-158b [6], paragraph F-47. Although the procedure for testing portland cement requires a Vicat penetration of $10 \pm 1 \mathrm{~mm}$, it was found that this range was too narrow for cement-lime specimens for easy repro- 
ducibility. Since it was found that small differences in consistency did not materially affect the expansion of the cement-lime specimens, the range was extended to $10 \pm 5 \mathrm{~mm}$. In a few instances specimens were used even though the penetrations were not within this range, generally because there was insufficient material to prepare additional specimens.

Immediately after the determination of the Vicat penetration, the entire supply of putty was remixed for approximately $15 \mathrm{sec}$. The remixed cement-lime putty was then molded into autoclave bar molds according to the procedure given in SS-C-158b, paragraph F-61. The bar molds provided for test specimens having a cross section 1 in. by 1 in. and of 10 -in. effective gage length, SS-C-158b, paragraph F-43 [6].

Immediately after molding each specimen, its exposed surface was covered with a strip of waxed paper pressed down on the mold. This waxed paper reduced surface evaporation and minimized the breakage, during curing, caused by shrinkage cracks. The test specimens were stored in the molds in a moist closet for at least $20 \mathrm{hrs}$, following the requirements of SS-C-158b, paragraph $\mathrm{F}-62$.

The cement-lime-sand mortars were prepared in accordance with Federal Specification SS-C$181 \mathrm{~b}$ [12], considering the mixture of cement and lime as masonry cement. The consistency of all mortars was adjusted to a flow of $110 \pm 2$. The casting of the mortar into autoclave bar molds and subsequent treatment were similar to that of the cement-lime putties.

At $23 \pm 1 \mathrm{hr}$ after molding the specimens, they were removed from the moist closet, measured for length, and placed in the autoclaves at room temperature. The autoclaves were immediately closed, and heat was applied.

After autoclaving, the specimens for the most part were submerged in water and cooled to $21^{\circ} \mathrm{C}$ before measuring the length, as required in the procedure of autoclaving as given in Federal Specification SS-C-158b, paragraph F-63f [6]. It was found necessary, however, to cool those specimens that exhibited very high expansions $(10 \%$ or more) in air to $21^{\circ} \mathrm{C}$, because when cooled in water the greatly expanded specimens were apt to disintegrate.

For expansions under 2.5 percent, the comparator described in paragraph $\mathrm{F}-45$ of SS-C$158 \mathrm{~b}$ [6] was used. For higher expansions, methods giving values to within a hundredth of an inch were used.

\section{Autoclaves and Methods of Autoclaving}

Four autoclaves were used in this investigationone, horizontal, gas-fired; and three, vertical, electrically heated. One of the latter was equipped with a special device for the continuous observation of the expanding bar specimens.

\section{Horizontal Gas-Fired Autoclave}

The detailed description of the horizontal, gasfired autoclave will be omitted because it was not used in this investigation after it was found that the expansions obtained with it were somewhat erratic and did not agree well with the concordant results obtained with the three vertical autoclaves that were electrically heated.

It was found, for example, that the cement-lime specimens placed in the upper part of the chamber of the gas-fired autoclave expanded more than companion specimens placed in the lower part. It is believed that the reason for this is the tendency for the steam to become superheated in the upper portion of a horizontal autoclave that is gasfired.

\section{Vertical, Electrically Heated Autoclaves}

The three electrically heated autoclaves were of such a design that they met the requirements of Federal Specification SS-C-158b [6] for an autoclave to be used in the testing of portland cement. Since preliminary experiments showed that the rate of heating cement-lime specimens markedly affected the resultant expansion of the bars, the rate of heating each autoclave to $295 \mathrm{lb} / \mathrm{in} .^{2}$ was determined. It can be seen from figure 3 that with each autoclave the pressure of the saturated steam in the autoclave was raised to a gage pressure of $295 \mathrm{lb} / \mathrm{in}^{2}$ in 1 to $1 \frac{1 / 4}{4} \mathrm{hr}$, as required by the standard method for testing cement [6].

Autoclaves designated as 1 and 2 were used in the preliminary experiments wherein the cement-lime and cement-lime-sand specimens were autoclaved at gage pressures of 25,120 , and $295 \mathrm{lb} / \mathrm{in}^{2}$ and also in the bulk of the work where the autoclaving was done in accordance with the standard method for portland cement specimens (295 $\left.\mathrm{lb} / \mathrm{in}^{2}\right)$. 


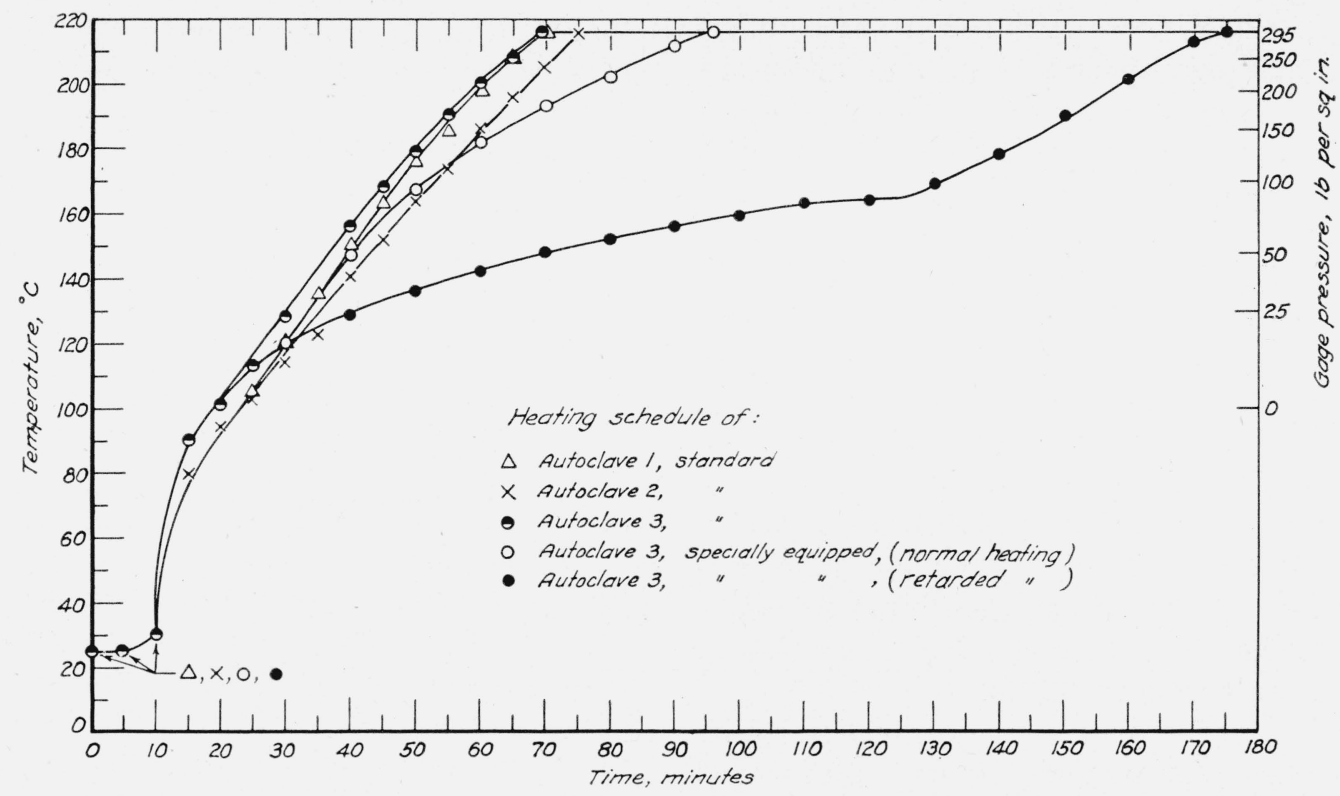

Figure 3. Time-temperature curves of heating autoclaves to $216^{\circ} \mathrm{C}$ (equivalent to steam-gage pressure of $295 \mathrm{lb} / \mathrm{in} .^{2}$ ).

The method of autoclaving at $295 \mathrm{lb} / \mathrm{in}^{2}{ }^{2}$ was used in accordance with ASTM and Federal Specifications for testing portland cement. When the autoclaving was done at 25 and $120 \mathrm{lb} / \mathrm{in}^{2}$, the heating schedule of the standard autoclaves 1 and 2 (fig. 3) was followed to the required pressure, after which the pressure, or temperature, was maintained by manual control.

\section{Special Autoclave for Continuous Observation of Expansion ${ }^{3}$}

Figure 4 shows the apparatus that permitted continuous observation of the expansion of a bar (cement or cement-lime specimens) during the course of autoclaving. Figure 5 is a schematic drawing of the specially equipped, electrically heated autoclave illustrated in figure 4 . The device consisted of a high-pressure gage-glass chamber, A, mounted on top of autoclave 3 by means of a short length of threaded high-pressure pipe screwed into a threaded hole tapped through the cover plate of the autoclave. A free-moving square steel rod, B, extended from the inside of the autoclave through the connecting pipe into the gage-glass chamber. The top of the rod was pointed in order to serve as a reference. The lower end, which extended through the connecting

3 Special acknowledgment is due Emil Trattner for his graciousness in consenting to the description of his ingeneously designed autoclave, which permitted, for the first time, the observation of a test specimen during the course of autoclaving. pipe into the autoclave chamber, was provided with a steel disk, $\mathrm{K}$, that rested on the top of the test specimen, $\mathrm{H}$, which was held vertically in a rack, $R$, placed in the chamber of the autoclave. With this arrangement, an expanding test bar caused the steel rod to rise in the gage-glass chamber, and the movement could be observed by sighting through the parallel glass windows of the chamber. By having the rod square, passage of steam and condensed water in and out of the gage-glass chamber was assured. A small steel spring, I, was attached to one side of the steel rod to prevent the rod from falling out of the gageglass chamber while the cover plate was being; placed and removed.

It was found that bars that were being continuously wetted during autoclaving gave erratic and unusually large expansions. Therefore, it was necessary to divert condensed dripping water away from the test specimen located directly below the gage-glass chamber, and hence a copper flashing, J, (fig. 5) was attached to the movable square steel rod directly above the steel disk that rested on the top of the specimen. As a check on the performance of the test bar carrying the movable steel rod, a duplicate bar was always placed in the same autoclave away from the dripping condensed water; after autoclaving, both bars were measured with a comparator.

In operation, the test bar was placed in a rack 


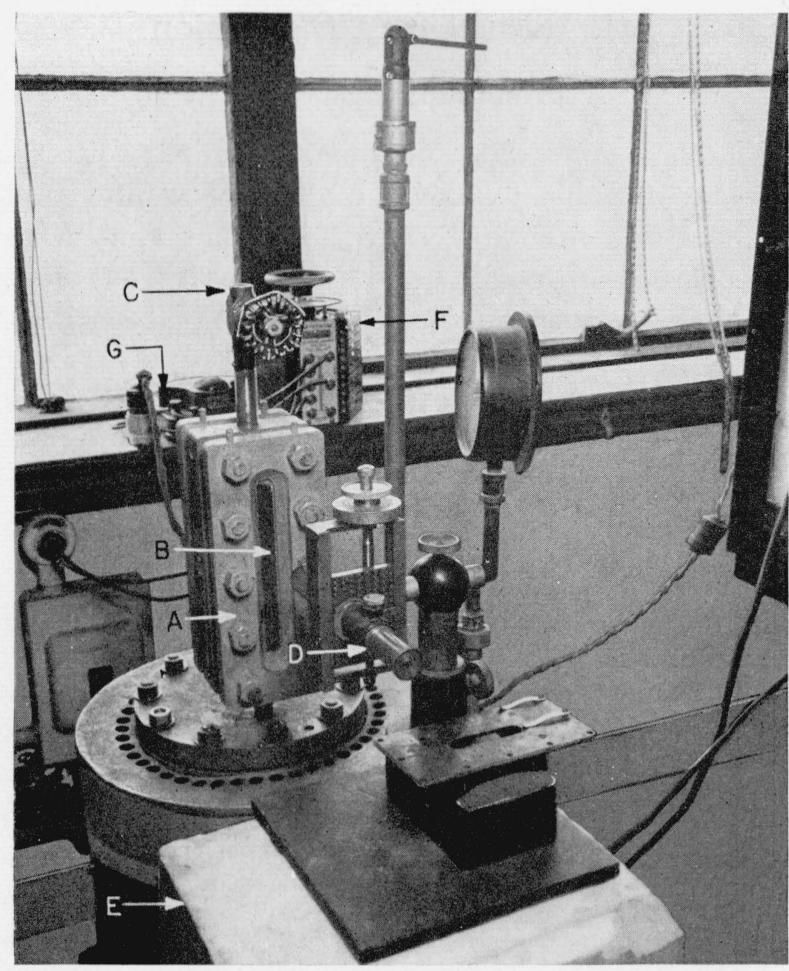

Figure 4. Assembly of specially equipped autoclave for continuous observation of expanding bar-specimens during autoclaving.

A, Gage-glass chamber mounted on top of autoclave; B, movable square steel rod extending from top of specimen into the gage-glass chamber; $\mathrm{C}$, vent valve; D, cathetometer for measuring movement of movable steel rod; $\mathrm{E}$, stone base for cathetometer; F, variac; G, voltmeter.

in the autoclave, and the cover plate with the attached gage-glass chamber, together with the inserted steel rod held in place by the restricting spring, was lowered into place in such a manner that the steel disk at the lower end of the rod came to rest on the flat top of the test bar. ${ }^{4}$ The cover plate was then bolted down and the vent valve, C, was opened.

The position of the point of the free-moying steel rod was located by means of the cathetometer, D, (fig. 4), which was firmly mounted on a stone base, E.

The heaters were then turned on, and the water in the bottom of the autoclave was brought to boiling. After the air had been displaced by steam, the vent valve, C, was closed. The autoclave was heated to a final pressure of $295 \mathrm{lb} / \mathrm{in}^{2}$, at which pressure the thermometer reading was $216^{\circ} \mathrm{C}$. The rate of heating was controlled

4 The steel reference point that normally would be present at the top of the test bar, for measurement with a comparator, had been removed during fabrication.

Expansive Characteristics of Limes

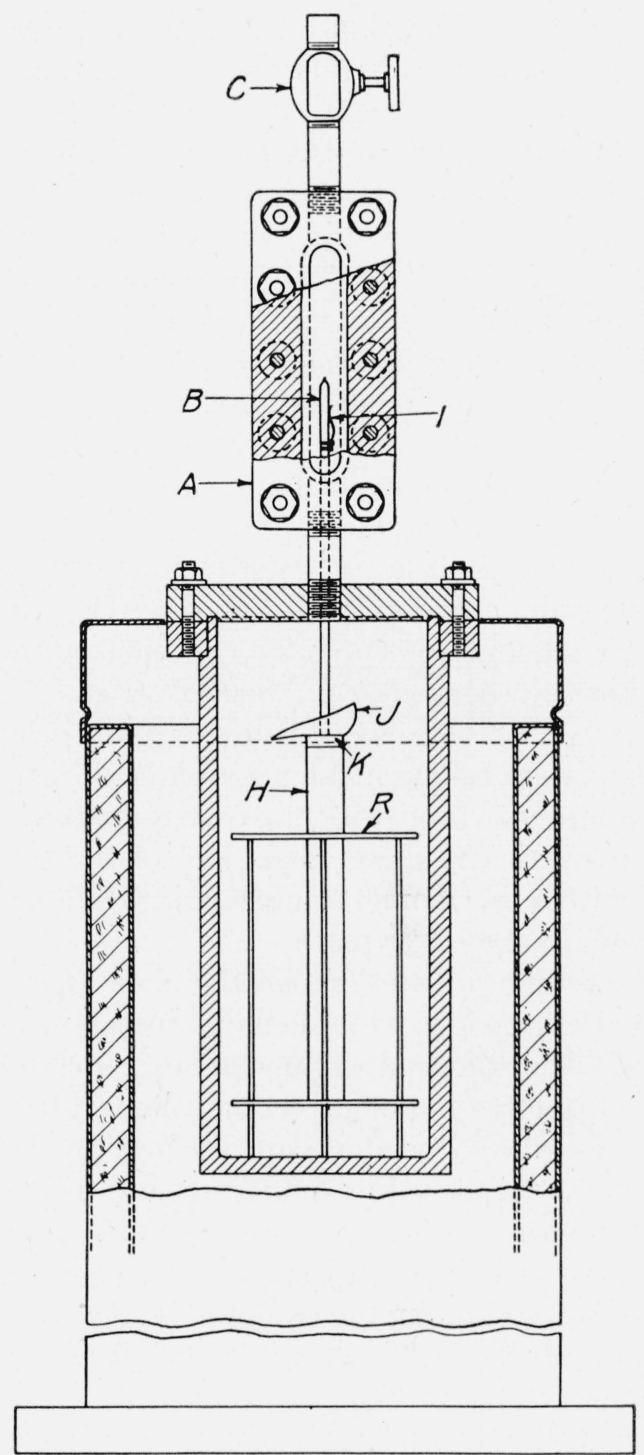

Figure 5. Details of gage-glass chamber and movable steel rod.

A, Gage-glass chamber; B, movable square steel rod; C, vent valve; $\mathrm{H}$, barspecimen; I, spring for holding movable square steel rod in place while assembling apparatus; J, copper flashing attached to movable steel rod to divert condensing water running down rod away from specimen $\mathrm{H} ; \mathrm{K}$, steel disk attached to lower end of movable steel rod and resting on top of specimen; $\mathrm{R}$, rack for holding specimen upright.

manually by means of the several heating units of the autoclave. A variac, F, connected through a voltmeter, $\mathrm{G}$, added flexibility to the control.

Readings of the position of the rising steel rod were obtained easily until the vent was closed. Immediately thereafter, readings could not be taken with the cathetometer because of the condensation of drops of water on the inside of the glass windows of the gage-glass chamber. This 
condition lasted for about 1 or $2 \mathrm{~min}$. However, since the gage-glass chamber acted as a condenser, the interior soon became completely filled with water. $^{5}$ From then on, the point of the steel rod was clearly visible.

The shortest time within which the gage pressure could be raised to $295 \mathrm{lb} / \mathrm{in}^{2}{ }^{2}$ was about $97 \mathrm{~min}$., compared to the $70 \mathrm{~min}$. required to heat the same autoclave without the gage-glass chamber. This $97 \mathrm{~min}$. is beyond the upper limit of $1 \frac{1}{4} \mathrm{hr}$ specified in SS-C-158b [6]. The increase in time was caused by the greater heat input required by the condensing and refluxing of the water in the gageglass chamber and by the greater heat capacity of the specially equipped autoclave. The normal heating schedule of specially equipped autoclave 3 is shown in figure 3 .

Throughout the entire course of autoclaving, readings were taken of the position of the point of the moving steel rod with the cathetometer, of the pressure with the steam gage, and of the temperature with a thermometer inserted into a thermometer well in the cover plate.

The design of the apparatus was such that thermal expansions were included in the measurements. The thermal expansions of concern were those of the free-moving steel rod, the test bar, and the part of the autoclave below the lower end of the test bar. This combined thermal expansion was determined by inserting a test specimen that had previously been autoclaved at a gage pressure of $295 \mathrm{lb} / \mathrm{in}^{2}{ }^{2}$, setting up the equipment as in a normal test procedure, and heating to $295 \mathrm{lb} / \mathrm{in}^{2}{ }^{2}$. The movement of the point of the steel rod was observed and taken as the thermal expansion of the combined parts. The previously autoclaved test bar used in this experiment was measured with a comparator before and after autoclaving and was found to have shown no subsequent expansion. These results were checked by replacing the cement-lime test bar with a steel bar of equal length and of known coefficient of expansion. The magnitude of the thermal expansion compared with the observed total expansion of the test specimens will be discussed later.

${ }^{5}$ To compensate for water condensed in the gage-glass chamber, $590 \mathrm{ml}$ of water, rather than the usual $500 \mathrm{ml}$, was placed in this special autoclave at the start.

\section{Results and Discussion}

\section{Preliminary Experiments}

Table 3 gives data on some preliminary experiments on the expansion of cement-lime and cement-lime-standard sand specimens that were autoclaved at steam-gage pressures of 25,120 , and $295 \mathrm{lb} / \mathrm{in} .^{2}$, respectively. It can be seen that, without exception, increasing the pressure of autoclaving from 25 to 120 to $295 \mathrm{lb} / \mathrm{in}^{2}$ was attended by an increase in the percentage of the linear expansion.

Also, increasing the proportion of lime to cement from $2 \mathrm{C}: 1 \mathrm{~L}$ to $1 \mathrm{C}: 1 \mathrm{~L}$ invariably resulted in a marked increase in expansion at each pressure of autoclaving. Increasing the proportion of lime in the cement-lime specimens results in a decrease in the strength of the specimen and therefore a decrease in the ability of the specimen to resist expansive forces. It is believed that an increase in expansion attending a decrease in the strength accounts for the relatively high expansion values of the $1 \mathrm{C}: 1 \mathrm{~L}: 5 \mathrm{~S}$ group. In fact, the weakness of the sanded bars and the difficulty of their preparation and handling discouraged further work with sanded specimens. In addition, the possibility of a variable being introduced because of a probable pozzolanic reaction between the lime and sand during autoclaving further operated against their use.

Figure 6 shows the increase in expansion at-

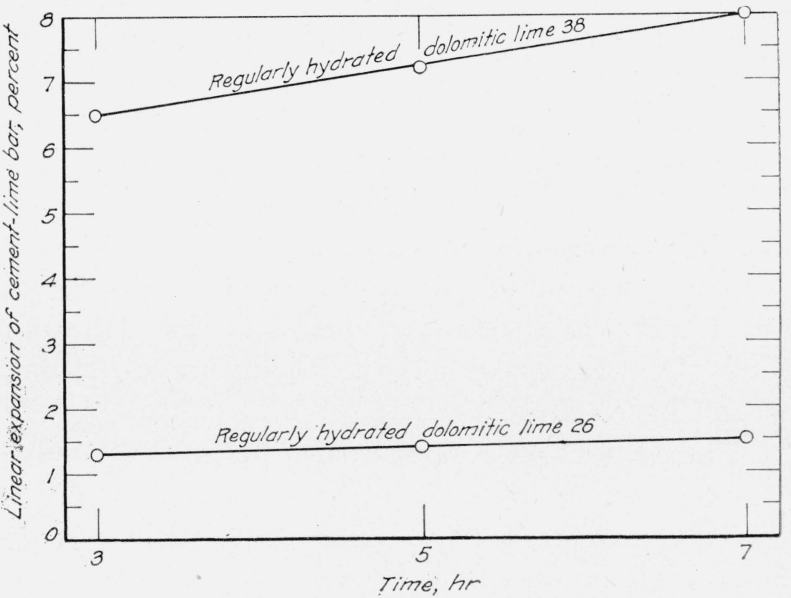

Figure 6. Increase in expansion of cement-lime bars attending increase in time of autoclaving at gage-pressure. of $25 \mathrm{lb} / \mathrm{in}^{2}$. 
TABLE 3. Expansion of cement-lime and cement-lime-standard sand bars autoclaved at steam-gage pressures of 25,120 , and $295 \mathrm{lb} / \mathrm{in}^{2} .^{2}$ for $3 \mathrm{hr}$, respectively

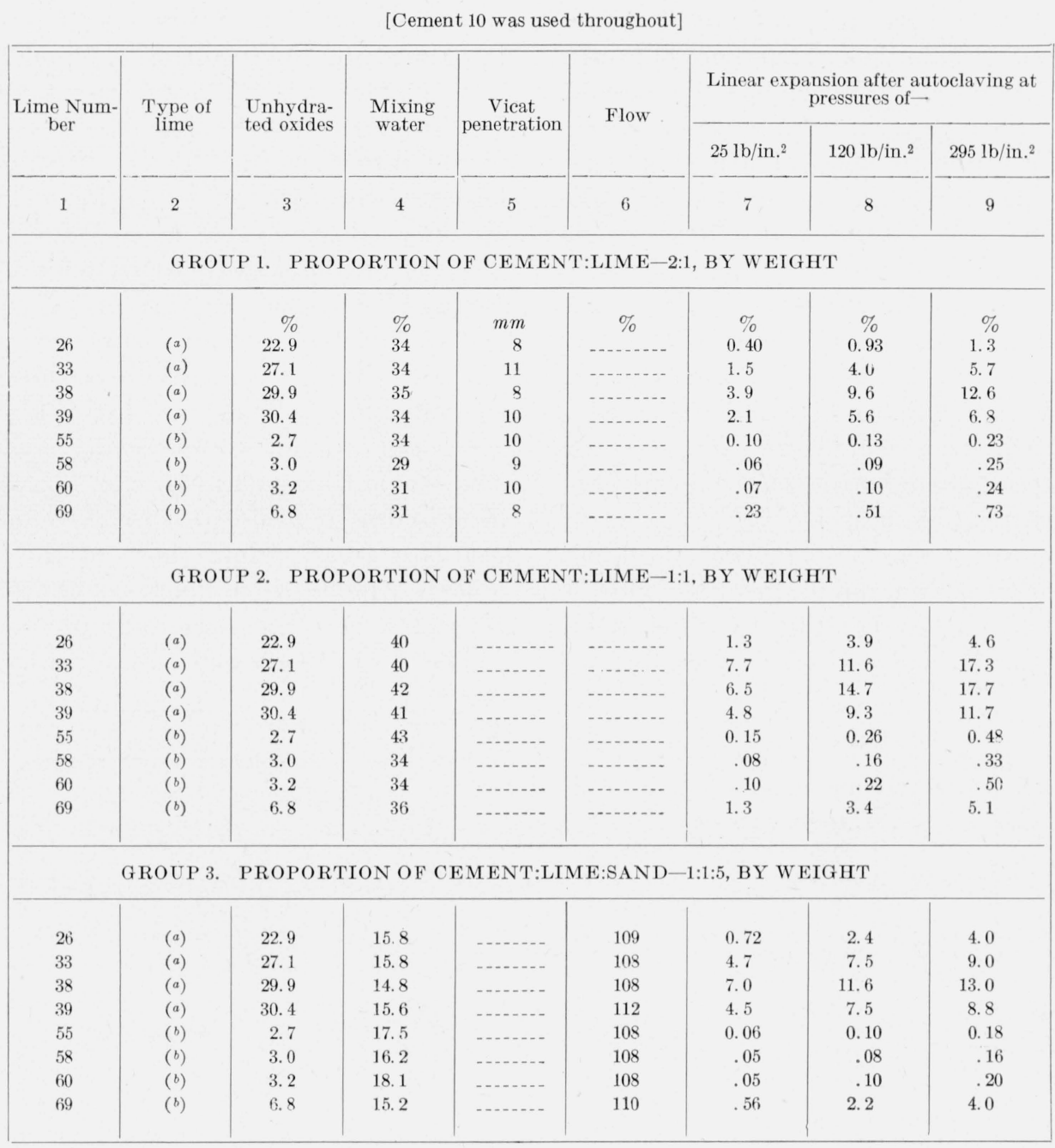

a Regularly hydrated dolomitic lime.

${ }^{b}$ Highly hydrated dolomitic lime.

tending an increase in the time of autoclaving specimens containing hydrated limes (26 and 38) at a pressure of $25 \mathrm{lb} / \mathrm{in}^{2}$. The expansion curves indicate that the ultimate expansion had not been reached after $7 \mathrm{hr}$ of autoclaving. The investigation of the effect of time of autoclaving at a pressure of $25 \mathrm{lb} / \mathrm{in}^{2}$. was not extended beyond $7 \mathrm{hr}$, because even that is too long for a continuous laboratory test procedure.

It became evident from these preliminary experiments that the pressure of autoclaving is an important factor with respect to the magnitude of the expansion. It is also evident that at lower pressures the total expansion is not reached within a practicable time. It was found, however, that cement-lime bars as well as portland-cement bars underwent no further expansion at $295 \mathrm{lb} / \mathrm{in}^{2}$. when autoclaved for periods in excess of $3 \mathrm{hr}$. It was decided, therefore, to abandon further work with lower pressures and to limit all further experiments to autoclaving for $3 \mathrm{hr}$ at a pressure of $295 \mathrm{lb} /$ in $^{2}$.

\section{Effect of Increasing Proportion of Hydrated Lime on Expansion of Cement-Lime Bars}

Table 1 (cols. 11, 12, and 13) gives data on the expansion of cement-lime bars prepared in the proportions of $2 \mathrm{C}: 1 \mathrm{~L}, 1 \mathrm{C}: 1 \mathrm{~L}$, and $1 \mathrm{C}: 2 \mathrm{~L}$, 
by weight, respectively, and autoclaved for $3 \mathrm{hr}$ at a gage pressure of $295 \mathrm{lb} / \mathrm{in}^{2}$.

The values for the percentage of expansion recorded in columns 11 and 13 are averages obtained by single operators from duplicate specimens. Forty-three of the values in column 12 represent the averages for duplicate determinations of three independent operators; the remainder are the average of duplicate determinations by a single operator.

Figures 7, 8, and 9 show the respective expansions of the $2 \mathrm{C}: 1 \mathrm{~L}, 1 \mathrm{C}: 1 \mathrm{~L}$, and $1 \mathrm{C}: 2 \mathrm{~L}$ bars (cols. 11, 12, and 13 of table 1), plotted against the percentages of unhydrated oxides (col. 10 of table 1) in the hydrated lime used in preparing the bars. Several salient features are evident from table 1 , and figures 7,8 , and 9 .

From the figures it can be seen that the limes are distributed into two major groups. One is composed entirely of the regularly hydrated dolomitic limes (series B) and is characterized by con- taining those limes having the highest percentage of unhydrated oxides and the highest percentage of expansion. The other group is composed of the remaining limes (series A, C, and D).

The high-calcium limes (series $\mathbf{A}$ ) are characterized in general by having the lowest percentages of unhydrated oxides ( 0 to 3.9 percent) and the lowest percentages of expansion. This can best be observed from table 1 .

Most of the highly hydrated dolomitic limes (series C) have percentages of unhydrated oxides (1.4 to 4.0 percent) and, with one exception, expansions that are comparable to those of the highcalcium limes. These are limes 49 to 65 , inclusive, and are all commercially available limes. The others (limes 66 to 76 , incl.) have percentages of unhydrated oxides (5.1 to 12.6$)$ and expansions that are greater than those of the high-calcium limes. Among these limes are 67, 68, 71, 75, and 76 , which were experimentally produced.

The four magnesian limes (series D) exhibit

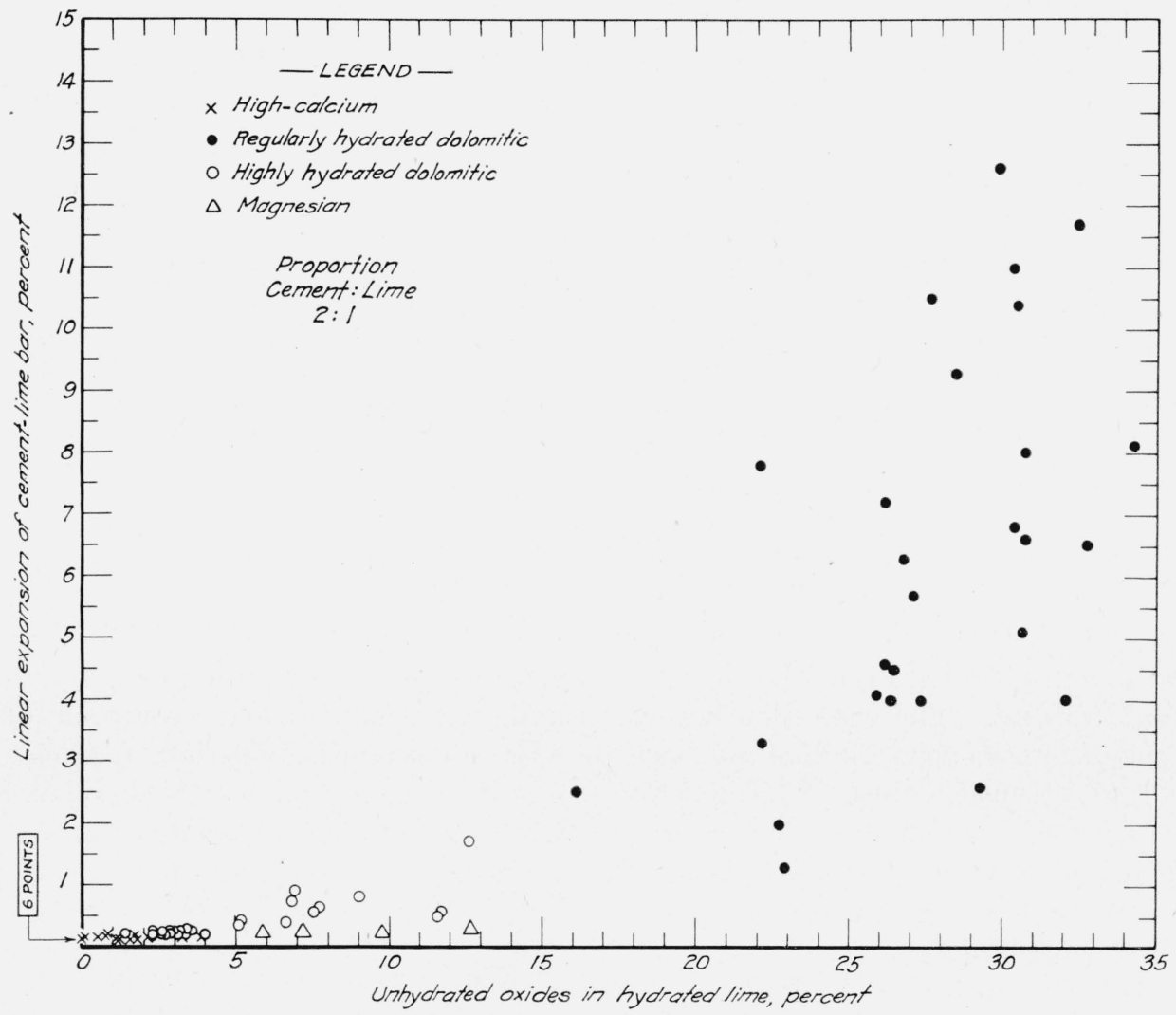

FIgURE 7. Linear expansion of cement-lime bars prepared with hydrated limes containing various amounts of unhydrated oxides, in the proportion of 2 cement to 1 lime (by weight) and subsequently autoclaved for 3 hr at a gage pressure of $295 \mathrm{lb} / \mathrm{in}^{2}$.

The specimens were all prepared with cement 10, which, without the addition of hydrated lime, had a linear expansion of 0.11 percent. 


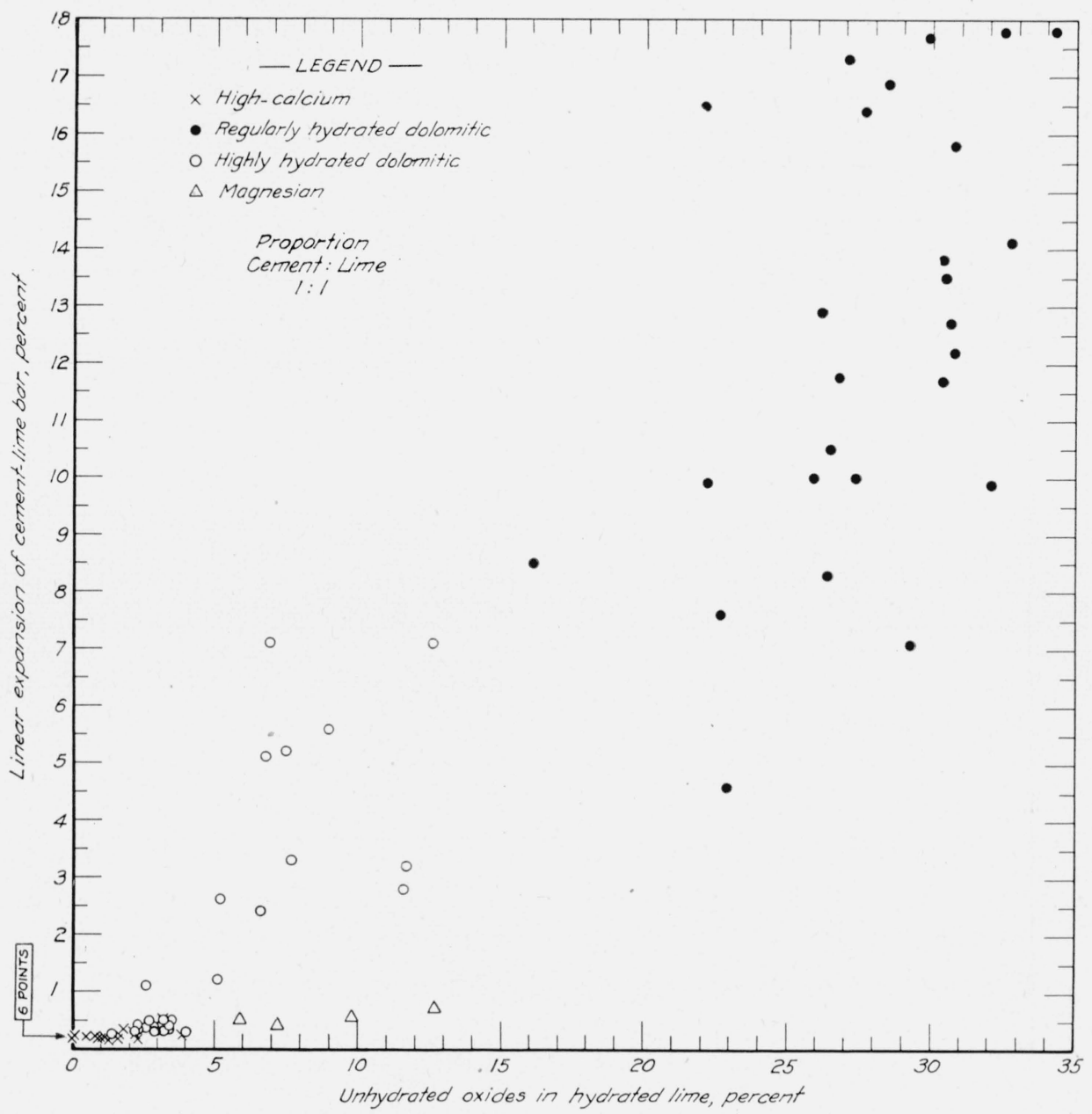

FIGURE 8. Linear expansion of cement-lime bars prepared with hydrated limes containing various amounts of unhydrated oxides, in the proportion of 1 cement to 1 lime (by weight) and subsequently autoclaved for 3 hr at a gage pressure of $295 \mathrm{lb} / \mathrm{in}^{2}$.

The specimens were all prepared with cement 10 , wh ich, without the addition of hydrated lime, had a linear expansion of 0.11 percent.

unique behavior in that each magnesian lime shows a lower percentage of expansion than other limes with a comparable percentage of unhydrated oxides.

From table 1 it can be seen that, for the limes of each series, an increase in the proportion of lime in the cement-lime bars is, without exception, attended by an increase in expansion. This relation is also shown in figure 10, where the percentages of linear expansion of the $2 \mathrm{C}: 1 \mathrm{~L}, 1 \mathrm{C}: 1 \mathrm{~L}$, and $1 \mathrm{C}: 2 \mathrm{~L}$ bars are plotted consecutively.

Figure 10 shows, again, that as a group the high-calcium limes give the lowest expansions in the three cement-lime proportions, and that a majority of the highly hydrated dolomitic limes give expansions comparable to the high-calcium limes. It also reveals that the expansions of the remaining 11 highly hydrated dolomitic limes, which include the six experimental limes, are intermediate between those of the high-calcium and the regularly hydrated dolomitic limes. However, in the $2 \mathrm{C}: 1 \mathrm{~L}$ proportion, the expansions of the high-calcium and all of the highly hydrated dolomitic limes fall within a narrow range- with only one exception, under 1.0 percent. As the proportion of the lime in the bar increases from $2 \mathrm{C}: 1 \mathrm{~L}$ to $1 \mathrm{C}: 1 \mathrm{~L}$, the spread in expansion is greatly accentuated for those highly hydrated dolomitic limes having expansions beyond the range of the high-calcium limes. The spread in expansion is even more accentuated in the $1 \mathrm{C}: 2 \mathrm{~L}$ bars. 


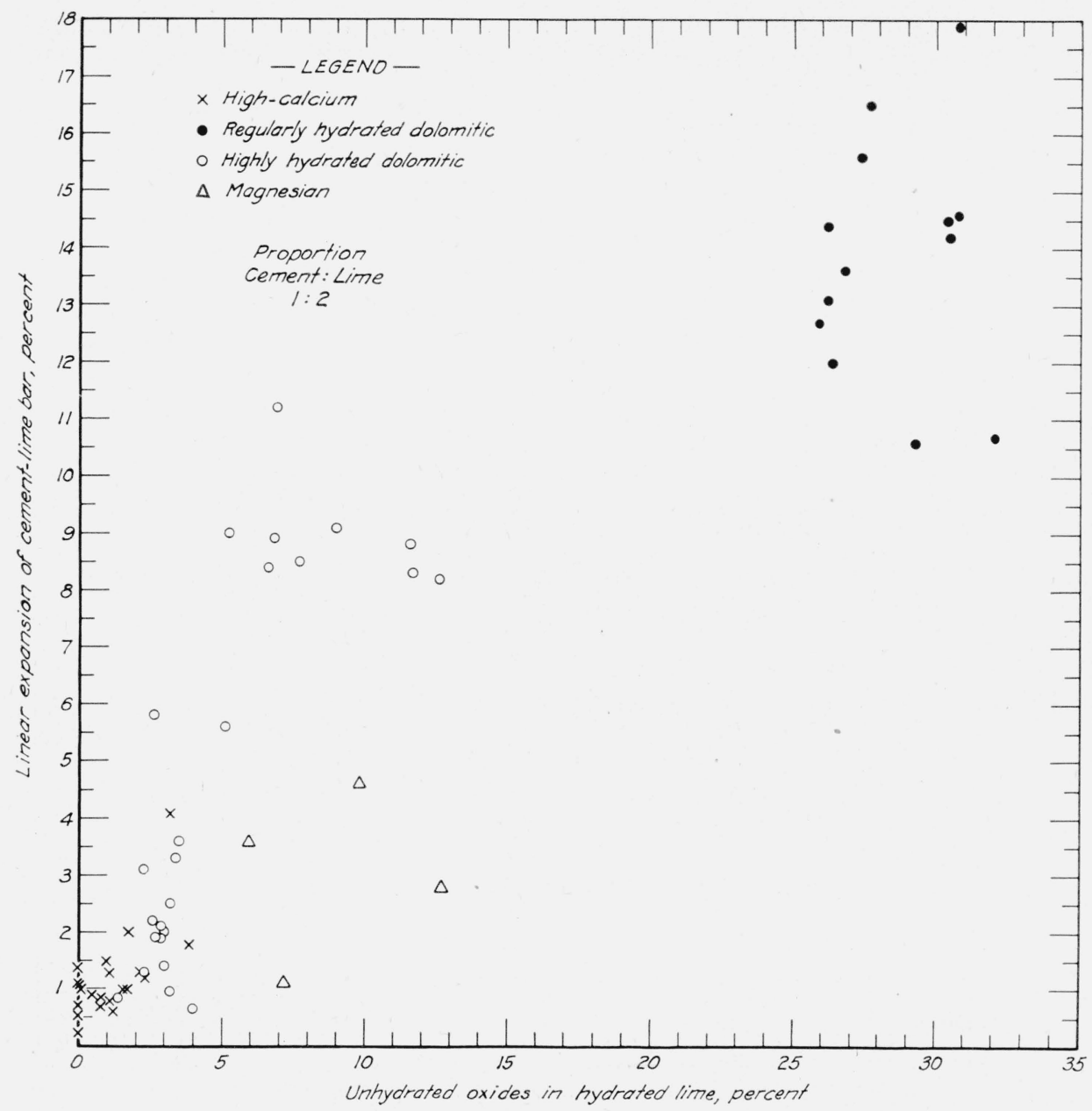

FIGURE 9. Linear expansion of cement-lime bars prepared with hydrated limes containing various amounts of unhydrated oxides in the proportion of 1 cement to 2 lime (by weight) and subsequently autoclaved for $3 \mathrm{hr}$ at a gage pressure of $295 \mathrm{lb} / \mathrm{in}^{2}$.

The specimens were a ll prepared with cement 10, which, without the addition of hydrated lime, had a linear expansion of 0.11 percent.

In figures 7, 8, and 9 the expansions of the $2 \mathrm{C}: 1 \mathrm{~L}, 1 \mathrm{C}: 1 \mathrm{~L}$, and $1 \mathrm{C}: 2 \mathrm{~L}$ bars were plotted in each case against the calculated percentage of unhydrated oxide in the constituent lime. However, the percentages of unhydrated oxide in the $2 \mathrm{C}: 1 \mathrm{~L}, 1 \mathrm{C}: 1 \mathrm{~L}$, and $1 \mathrm{C}: 2 \mathrm{~L}$ mixes are respectively one-third, one-half, and two-thirds of that of the percentage of unhydrated oxide in the lime. Accordingly, figure 11 shows the relation between the percentages of expansion of $2 \mathrm{C}: 1 \mathrm{~L}, 1 \mathrm{C}: 1 \mathrm{~L}$, and $1 \mathrm{C}: 2 \mathrm{~L}$ bars and the corresponding percentage of unhydrated oxide in the dry mix.

Once more, it can be seen from figure 11, where the percentages of expansion of the $2 \mathrm{C}: 1 \mathrm{~L}, 1 \mathrm{C}: 1 \mathrm{~L}$, and $1 \mathrm{C}: 2 \mathrm{~L}$ bars are plotted side by side, that an increase in the proportion of lime in the bars is accompanied by an increase in expansion. But more important, the three graphs making up figure 11 show that the percentage of unhydrated oxide in the mix must be low if there is to be assurance that the expansion will also be low. It is also evident that the limiting percentage is not the same for each proportion of cement to lime. This percentage apparently narrows as the quantity of cement decreases and the bars correspondingly become weaker and are less able to resist the expansive forces attending the hydration of the unhydrated oxide. For example, with the $2 \mathrm{C}: 1 \mathrm{~L}$ bars, the total unhydrated oxide may be as high as 4 percent and yet the expansion of the bars remain below 1 percent. With the weaker $1 \mathrm{C}: 1 \mathrm{~L}$ bars, the percentage of unhydrated oxide that 


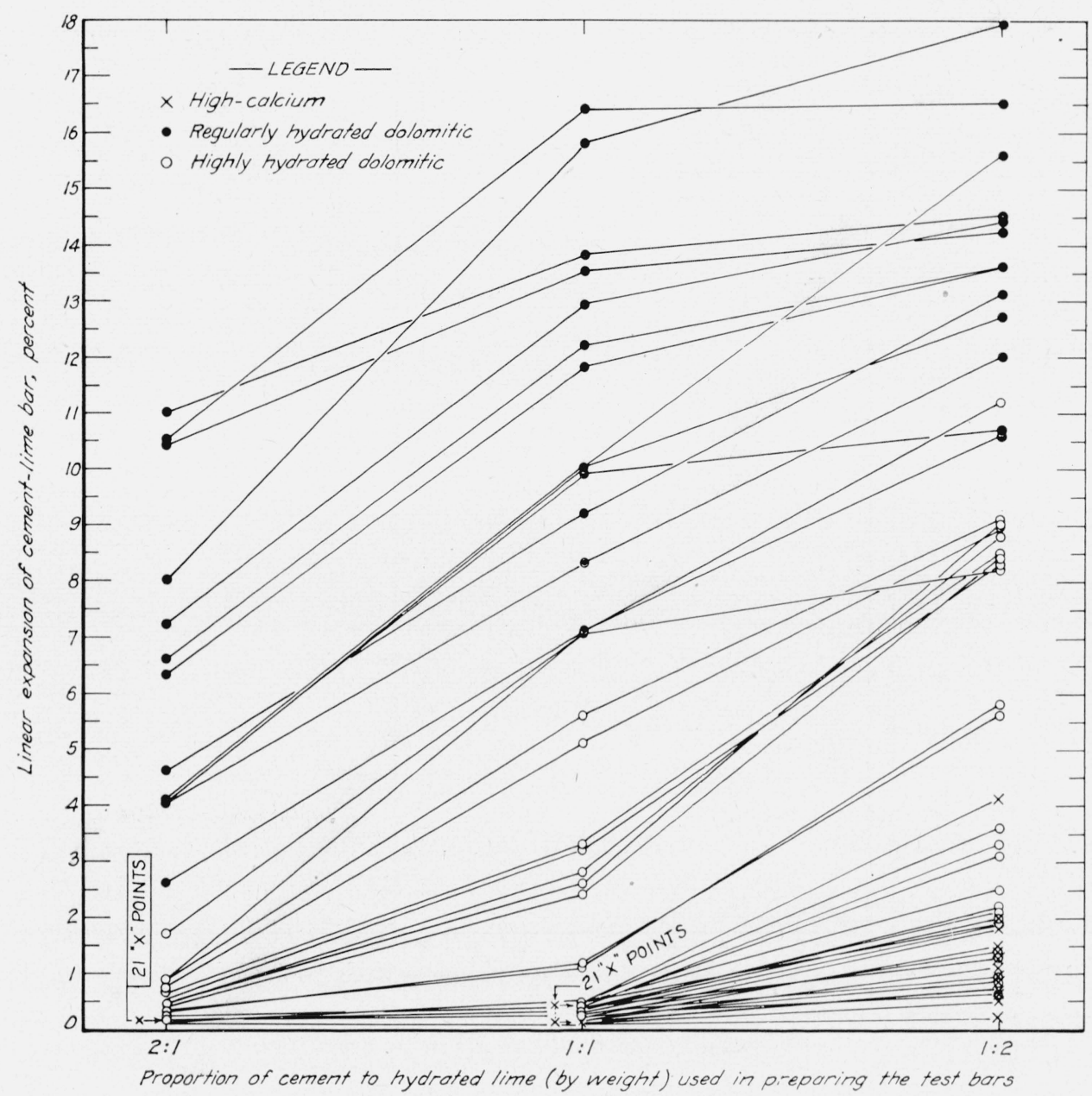

Figure 10. Increase in linear expansion attending an increase in the proportion of lime in cement-lime bars autoclaved for $3 \mathrm{hr}$ at a gage pressure of $295 \mathrm{lb} / \mathrm{in.}^{2}$

can be tolerated appears to be less, because at 4 percent the expansion may exceed 6 percent. With the still weaker $1 \mathrm{C}: 2 \mathrm{~L}$ bars, the expansion of the bars with 4 percent of unhydrated oxide may reach values in the neighborhood of 10 percent. In fact, even with little or no unhydrated oxide, the bars of the $1 \mathrm{C}: 2 \mathrm{~L}$ series show expansions considerably greater than those of the other two mixes. It is not known whether this can be attributed in part to the cement itself because of the inability of these weak bars to resist the expansion of some of the constituents of the cement. It is interesting that the unique magnesian limes, which show less expansion than other imes with comparable percentage of unhydrated oxide, begin to show appreciable expansion in the $1 \mathrm{C}: 2 \mathrm{~L}$ bars.

\section{Reproducibility of Determining Percentage of} Expansion of 1 Cement:1 Lime Test Specimens

Table 4 gives data on the percentage of linear expansion obtained by three operators with duplicate cement-lime bars prepared in the proportion of 1 part cement to 1 part lime, by weight, and autoclaved at a steam-gage pressure of $295 \mathrm{lb} / \mathrm{in}^{2}$ for $3 \mathrm{hr}$. In addition, it gives for each operator the percentage of water used in fabricating the duplicate bars and the Vicat penetration of the cement-lime pastes. Forty-three samples of hydrated limes were selected for this study. In certain instances only one of an operator's duplicate bars was autoclaved.

Although the dates at which the tests were performed are not given in table 4 , the experiments 

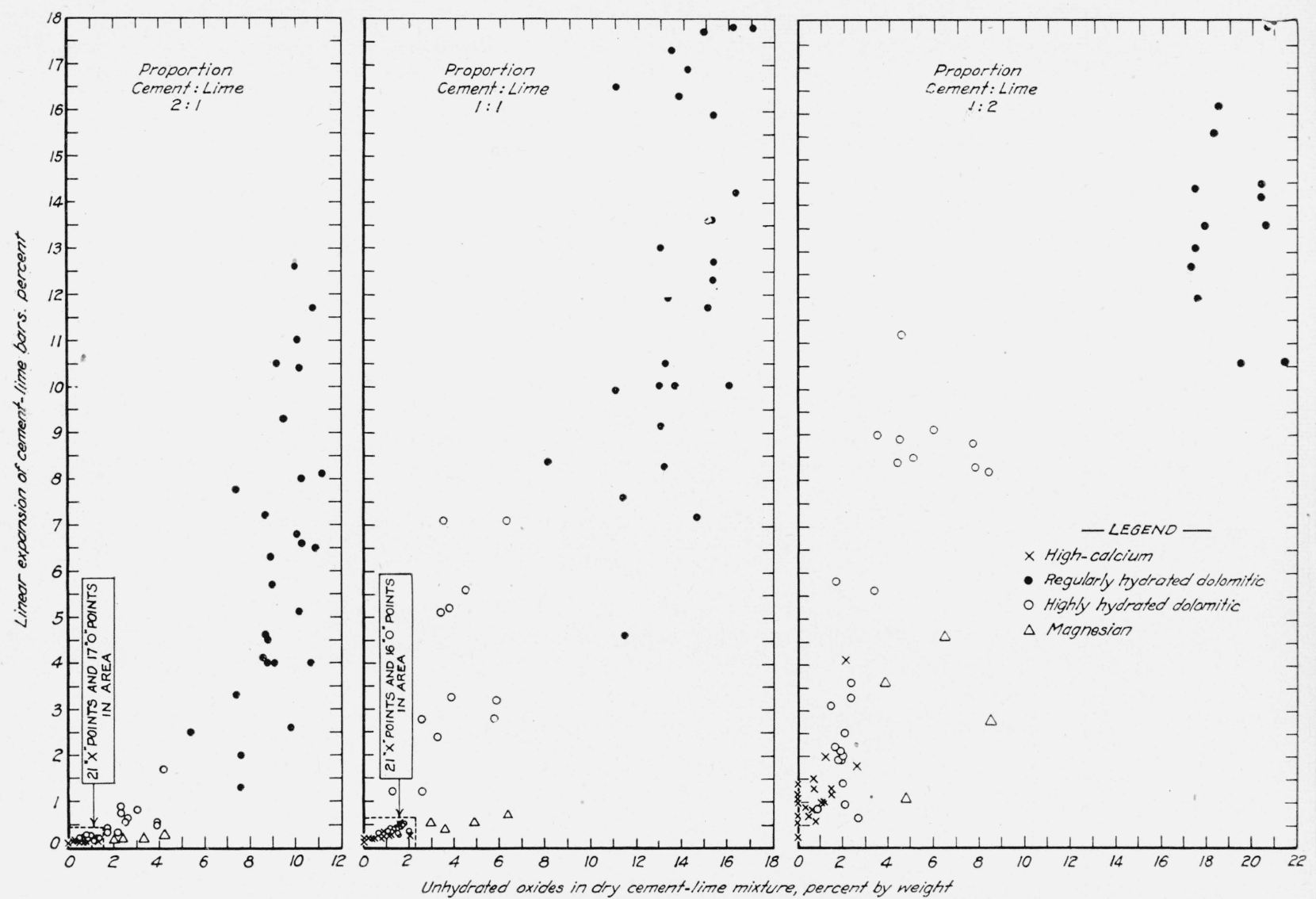

FIGURE 11. Relation between the percentage of expansion of $2 C: 1 L, 1 C: 1 L$, and $1 C: 2 L$ bars and the corresponding percentage of unhydrated oxides in the dry mix.

purposely were not made at the same time. The time period between the testing by operators $\mathrm{B}$ and $\mathrm{C}$ was approximately 1 month. Operator A did most of his testing about 1 year later.

It can be seen from table 4 that not only did the percentages of expansion of the two duplicate bars of each operator agree closely, but that the percentages of expansion obtained by the three different operators were in good agreement.

For the purpose of a statistical treatment, the various hydrated limes were divided into five nearly homogeneous groups. These include series A, high-calcium; series B, regularly hydrated dolomitic; series D, magnesian; and two subdivided groups of series C, highly hydrated dolomitic. One of these groups of series $\mathrm{C}$ included the highly hydrated dolomitic limes having percentages of both unhydrated oxide and expansion of the same order of magnitude as those of the high-calcium limes, namely, limes 49, 54, 56, $57,59,61$, and 65 , all of which had expansions of less than 0.40 percent. The other group contained the limes in series $\mathrm{C}$ having the high expansions: those ranging from 1.1 to 5.6 percent. A single classification analysis of variance [13] was made for each group to test whether there was a significant difference among the averages obtained by the three operators. No significant difference was found. ${ }^{6}$

\section{Effect of Different Portland Cements on Expan- sion of Cement-Lime Bars}

Table 5 gives data on the expansion of cementlime bars prepared with 17 cements (ranging in expansion from 0.00 to 0.30 percent). The 30 selected limes are grouped, as heretofore, in four series.

The values for the percentage of expansion of the 17 cements (tested in accordance with the

\footnotetext{
6 The authors thank Stephen W. Benedict for his statistical analysis of the reproducibility of determining the percentage of expansion of cement. lime test specimens.
} 
TABLE 4. Reproducibility obtained, by three independent operators, for the expansion of cement-lime bars prepared in the proportion of 1 cement:1 lime (by weight), and autoclaved at a steam-gage pressure of $295 \mathrm{lb} / \mathrm{sq}$ in..$^{2}$ for $3 \mathrm{hr}$. The specimens were all prepared with cement 10, which, without the addition of hydrated lime, had a linear expansion of 0.11 percent

\begin{tabular}{|c|c|c|c|c|c|c|c|c|c|c|c|c|c|c|}
\hline \multirow{3}{*}{$\begin{array}{c}\text { Lime } \\
\text { num- } \\
\text { ber }\end{array}$} & \multirow{3}{*}{$\begin{array}{c}\begin{array}{c}\text { Calcu- } \\
\text { lated } \\
\text { unhy- } \\
\text { drated } \\
\text { oxides }\end{array} \\
2\end{array}$} & \multicolumn{6}{|c|}{$\begin{array}{l}\text { Consistency (water, percent; and Vicat penetra- } \\
\text { tion, mm) of cement-lime pastes as obtained by } \\
\text { operator- }\end{array}$} & \multicolumn{6}{|c|}{$\begin{array}{l}\text { Linear expansion of duplicate cement-lime bars as } \\
\text { obtained by operator- }\end{array}$} & \multirow{3}{*}{$\begin{array}{c}\begin{array}{c}\text { Aver- } \\
\text { age of } \\
\text { linear } \\
\text { expan- } \\
\text { sion } \\
\text { values }\end{array} \\
15\end{array}$} \\
\hline & & \multicolumn{2}{|c|}{ A } & \multicolumn{2}{|c|}{$\mathrm{B}$} & \multicolumn{2}{|c|}{$\mathrm{C}$} & \multicolumn{2}{|c|}{ A } & \multicolumn{2}{|c|}{ B } & \multicolumn{2}{|c|}{$\mathrm{C}$} & \\
\hline & & 3 & 4 & 5 & 6 & 7 & 8 & 9 & 10 & 11 & 12 & 13 & 14 & \\
\hline \multicolumn{15}{|c|}{ SERIES A-HIGH-CALCIUM HYDRATED LIMES } \\
\hline & $\%$ & $\%$ & $m m$ & $\%$ & $m m$ & $\%$ & $m m$ & $\%$ & $\%$ & $\%$ & $\%$ & $\%$ & $\%$ & $\%$ \\
\hline 1 & 0.0 & 41 & 6 & 42 & 7 & 41 & 5 & 0.18 & 0.18 & -... & 0.18 & 0.18 & 0.20 & 0.18 \\
\hline 2 & .0 & 44 & 11 & 44 & 9 & 43 & 9 & .18 & .18 & -..- & .20 & -... & .20 & .19 \\
\hline 3 & .0 & 41 & 6 & 41 & 8 & 41 & 8 & .16 & .16 & -... & .15 & -..- & .16 & .16 \\
\hline 4 & .0 & 42 & 5 & 41 & 6 & 42 & 7 & .16 & .16 & 0.15 & .15 & .15 & .15 & .15 \\
\hline 5 & .0 & 38 & 14 & 38 & 10 & 38 & 12 & .14 & .14 & .13 & .13 & .13 & .13 & .13 \\
\hline 6 & .0 & 41 & 5 & 41 & 7 & 41 & 6 & .19 & .19 & .19 & .19 & .21 & .21 & .20 \\
\hline 11 & 1.0 & 41 & 9 & 41 & 8 & 40 & 6 & .19 & .19 & .19 & .19 & $.20^{\circ}$ & .20 & .19 \\
\hline 13 & 1.1 & 44 & 4 & 44 & 7 & 43 & 5 & .20 & .20 & -.. & .20 & .20 & .21 & .20 \\
\hline 14 & 1.2 & 41 & 7 & 41 & 8 & 41 & 7 & .18 & .18 & $\ldots$ & .18 & .19 & .19 & .18 \\
\hline 15 & 1.6 & 39 & 4 & 39 & 6 & 39 & 5 & .18 & .18 & $\ldots$ & .17 & .18 & .19 & .18 \\
\hline \multicolumn{15}{|c|}{ SERIES B-REGULARLY HYDRATED DOLOMITIC LIMES } \\
\hline 22 & 16.1 & 41 & 5 & 41 & 12 & 41 & 7 & -..- & 7.6 & 8.8 & 8. 9 & -... & 8.6 & 8.5 \\
\hline 27 & 25.9 & 40 & $\ldots$ & 39 & 17 & 38 & 3 & 9.8 & 10. 2 & 9.5 & 9.7 & 10.4 & 10.4 & 10.0 \\
\hline 28 & 26.2 & 38 & 6 & 38 & 7 & 39 & 9 & 12.5 & 12.5 & -... & 13.5 & .... & 13.1 & 12.9 \\
\hline 29 & 26.2 & 37 & 11 & 37 & 9 & 37 & 11 & 9.2 & 9.3 & 8.9 & 8.9 & 9.2 & 9.4 & 9.2 \\
\hline 30 & 26.4 & 37 & 7 & 37 & 11 & 38 & 8 & 8.3 & 8.4 & -... & 8.1 & 8.3 & 8.4 & 8.3 \\
\hline 32 & 26.8 & 37 & 10 & 38 & 20 & 39 & 11 & 11.6 & 11.6 & -... & 12.0 & .... & 12.0 & 11.8 \\
\hline 34 & 27.4 & 38 & 7 & 39 & 8 & 38 & 8 & 10. 1 & 10.1 & -... & 9.8 & 10.1 & 9.8 & 10.0 \\
\hline 35 & 27.7 & 37 & 9 & 38 & 13 & 38 & 10 & 16.3 & 16. 2 & 16.4 & 16.4 & 16.4 & 16.4 & 16.4 \\
\hline 36 & 28.5 & 41 & 8 & 42 & 13 & 41 & 4 & 17.4 & 17.4 & 16.4 & 16.4 & -... & 17.0 & 16.9 \\
\hline 37 & 29.3 & 39 & 4 & 38 & 5 & 38 & 5 & 6.9 & 6.9 & 7.3 & 7. 3 & -... & 7.3 & 7.1 \\
\hline 40 & 30.4 & 38 & 5 & 39 & 11 & 38 & 8 & -... & 14.0 & -... & 12. 6 & 14.1 & 14.3 & 13.8 \\
\hline 41 & 30.5 & 38 & 7 & 38 & 6 & 38 & 6 & ... & 13.8 & 13. 2 & 12. 7 & 13.8 & 14.0 & 13.5 \\
\hline 43 & 30.8 & 38 & 5 & 38 & 10 & 38 & 7 & 12.0 & 12.0 & .... & 12.4 & -... & 12.4 & 12. 2 \\
\hline 44 & 30.8 & 40 & 10 & 40 & 10 & 42 & 19 & 15.3 & 14.9 & -.. & 16.4 & 16.0 & 16.4 & 15.8 \\
\hline 45 & 32.1 & 42 & 6 & 41 & 5 & 42 & 7 & 9.3 & 9.1 & -.. & 10.1 & 10.6 & 10.5 & 9.9 \\
\hline 47 & 32.8 & 39 & 5 & 39 & 12 & 39 & 7 & 14. 2 & 14. 2 & $\ldots$ & 14. 5 & 14.0 & 13.8 & 14.1 \\
\hline \multicolumn{15}{|c|}{ SERIES C-HIGHLY HYDRATED DOLOMITIC LIMES } \\
\hline 49 & 1. 4 & 35 & $\ldots$ & 39 & 5 & 40 & 10 & 0.25 & 0.26 & 0.24 & 0.25 & 0.26 & 0.25 & 0.25 \\
\hline 53 & 2. 6 & 39 & 8 & 38 & 4 & 39 & 9 & .76 & .69 & 1.3 & 1.4 & 1.3 & 1.4 & 1.1 \\
\hline 54 & 2. 6 & 40 & 5 & 40 & 6 & 41 & 4 & .35 & .35 & 0.37 & 0.37 & -... & 0.38 & 0.36 \\
\hline 56 & 2. 9 & 37 & 11 & 37 & 12 & 37 & 8 & .24 & .25 & .... & .32 & -.. & .34 & .29 \\
\hline 57 & 2. 9 & 39 & 6 & 39 & 12 & 39 & 7 & .37 & .38 & .37 & .36 & .35 & .38 & .37 \\
\hline 59 & 3.0 & 39 & 6 & 39 & 9 & 39 & 7 & .34 & .35 & -... & .37 & .36 & .37 & .36 \\
\hline 61 & 3. 2 & 37 & 13 & 37 & 8 & 38 & 10 & .30 & .29 & .31 & .31 & .33 & .33 & .31 \\
\hline 65 & 4. 0 & 39 & 7 & 40 & 9 & 39 & 6 & .29 & .30 & .32 & .31 & .32 & .33 & .31 \\
\hline 67 & 5. 2 & 39 & 9 & 40 & 13 & 43 & 27 & 1.8 & 1.9 & 2. 9 & 2. 9 & -... & 3.7 & 2. 6 \\
\hline 68 & 6. 6 & 41 & 6 & 41 & 7 & 40 & 6 & 1.9 & 1.9 & 2.5 & 2.7 & -... & 2.8 & 2.4 \\
\hline 72 & 7.7 & 38 & 4 & 38 & 8 & 39 & 9 & 2. 7 & 2. 6 & 3.8 & 3.5 & 3.7 & 3.7 & 3.3 \\
\hline 73 & 9.0 & 36 & .... & 37 & 8 & 38 & 11 & 6.0 & 6.3 & 5. 0 & 5.0 & 5.5 & 5.7 & 5.6 \\
\hline 74 & 11.6 & 32 & 7 & 35 & 30 & 32 & 8 & 2. 3 & 2.3 & 3. 2 & 2.8 & 3.1 & 2.8 & 2.8 \\
\hline 75 & 11. 7 & 37 & 9 & 38 & 13 & 37 & 11 & 2.9 & 2.8 & 3.9 & 3.5 & 3.1 & 3.1 & 3.2 \\
\hline \multicolumn{15}{|c|}{ SERIES D-MAGNESIAN HYDRATED LIMES } \\
\hline 77 & 5.9 & 43 & 6 & 42 & 5 & 43 & 6 & 0.43 & 0.42 & & 0.54 & 0.57 & 0. 53 & 0.50 \\
\hline 78 & 7. 2 & 41 & 9 & 41 & 8 & 41 & 13 & .35 & .36 & 0.40 & .40 & .41 & .39 & .39 \\
\hline 80 & 12. 7 & 41 & 6 & 38 & 4 & 40 & 7 & .64 & .65 & .69 & .68 & .75 & .76 & .70 \\
\hline
\end{tabular}


TABLE 5. Effect of varying the cement on the expansion of cement-lime bars prepared in the proportion of 1 cement:1 lime (by weight), and autoclaved at a steam-gage pressure of $295 \mathrm{lb} / \mathrm{in} .^{2}$ for $3 \mathrm{hr}$

[The expansions of the 17 cements without the addition of limes ranged from 0.0 to 0.30 percent and are shown in brackets. The percentage of expansion obtained after subtracting the percentage of expansion of the cement from the percentage of expansion of the cement-lime bar is given in parentheses]

\begin{tabular}{|c|c|c|c|c|c|c|c|c|c|c|c|c|c|c|c|c|c|c|}
\hline \multirow{2}{*}{$\begin{array}{l}\text { Lime } \\
\text { num- } \\
\text { ber }\end{array}$} & \multirow{2}{*}{$\begin{array}{l}\text { Unhy- } \\
\text { drated } \\
\text { oxides }\end{array}$} & \multicolumn{17}{|c|}{ Linear expansion of cement-lime bars prepared with cements 1 to 17 , inclusive } \\
\hline & & $\begin{array}{c}1 \\
{[0.00]}\end{array}$ & $\stackrel{2}{[0.01}]$ & {$\left[\begin{array}{c}3 \\
{[0.01]}\end{array}\right.$} & $\begin{array}{c}4 \\
{[0.02]}\end{array}$ & $\begin{array}{c}5 \\
{[0.04]}\end{array}$ & $\begin{array}{c}6 \\
{[0.04]}\end{array}$ & {$\left[\begin{array}{c}7 \\
{[0.06]}\end{array}\right.$} & {$\left[\begin{array}{c}8 \\
{[0.07}\end{array}\right]$} & $\begin{array}{c}9 \\
{[0.11]}\end{array}$ & $\begin{array}{c}10 \\
{[0.11]}\end{array}$ & $\begin{array}{c}11 \\
{[0.11]}\end{array}$ & $\begin{array}{c}12 \\
{[0.17]}\end{array}$ & $\begin{array}{c}13 \\
{[0.18]}\end{array}$ & $\begin{array}{c}14 \\
{[0.19]}\end{array}$ & $\begin{array}{c}15 \\
{[0.23]}\end{array}$ & $\begin{array}{c}16 \\
{[0.27]}\end{array}$ & $\begin{array}{c}17 \\
{[0.30]}\end{array}$ \\
\hline \multicolumn{19}{|c|}{ SERIES A-HIGH-CALCIUM HYDRATED LIMES } \\
\hline & $\%$ & $\%$ & $\%$ & $\%$ & $\%$ & $\%$ & $\%$ & $\%$ & $\%$ & $\%$ & $\%$ & $\%$ & $\%$ & $\%$ & $\%$ & $\%$ & $\%$ & $\%$ \\
\hline 1 & 0.0 & $--\cdot$ & $--\cdot$ & $-\cdot$ & -.- & $\cdots$ & -.- & -- & $\left\{\begin{array}{l}0.11 \\
(.04)\end{array}\right.$ & -.. & $\begin{array}{l}0.19 \\
(.08)\end{array}$ & -.. & ... & $\begin{array}{l}0.43 \\
(.25)\end{array}$ & $\ldots$ & - & $\begin{array}{l}0.44 \\
(.17)\end{array}$ & -... \\
\hline 2 & .0 & -- & -.. & -- & $\cdots$ & -.. & $\left\{\begin{array}{l}0.07 \\
(.03)\end{array}\right.$ & -- & . & $\begin{array}{l}0.13 \\
(.02)\end{array}$ & $\begin{array}{l}0.20 \\
(.09)\end{array}$ &.- &.- & $\begin{array}{l}-. \\
\ldots \\
\ldots\end{array}$ & $\ldots$ & $\begin{array}{l}0.26 \\
(.03)\end{array}$ & $\begin{array}{l}-. \\
-\ldots\end{array}$ & $\ldots$ \\
\hline 3 & .0 &.- & -. & $-\cdot$ & -- & -.. & -- & $-\cdots$ & & -.. & $\begin{array}{l}0.16 \\
(.05)\end{array}$ & -.. & $\ldots$ & $\begin{array}{l}0.39 \\
(.21)\end{array}$ & -.. & $\begin{array}{l}\ldots . \\
\ldots-\end{array}$ & $\begin{array}{l}0.39 \\
(.12)\end{array}$ & $\ldots$ \\
\hline 4 & .0 & 0.03 & $\ldots$ & -. & 0.05 & -.. & -. & 0.08 & -.. & -.. & 0.15 & ... & -.. & -.. & -.. &.- & $\ldots$ & 0.29 \\
\hline & .0 & $(.03)$ & $\cdots$ & -.. & $(.03)$ & --. &.- & $(.02)$ & ... & -.. & $(.04)$ & ... & -.. & -.. & $\ldots$ & $\ldots$ & -.. & $(-.01)$ \\
\hline 5 & .0 & -.. & ... & -... & ... & $\ldots$ & $\left\{\begin{array}{l}0.07 \\
03\end{array}\right.$ & $\ldots$ & $\cdots$ & -.. & 0.13 & -.. & -- & 0.31 & 0.15 & 0.29 & 0.30 & -..- \\
\hline & & & & & ... & 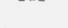 & ( $(.03)$ & -.- & -.. & $\cdots$ & $(.02)$ & -.- & -.. & $(.13)$ & $(-.04)$ & $(.06)$ & $(.03)$ & -...- \\
\hline 6 & .0 & 0.05 & -.- & -.- & -- & -.- & -.- & 0.11 & ... & -.. & 0.19 & -- &.-- & --- & $\ldots$ & --- & $\ldots$ & 0.39 \\
\hline & & ( $(.05)$ & $\cdots$ & -.. & $\cdots$ & $\cdots$ & (-.- & $(.05)$ & -.. & -- & $(.08)$ & -.. & -- & -.. & -.. & -.- & $-\cdots$ & $(.09)$ \\
\hline 12 & 1.1 & ... & -.. & ... & -..- & ... & $\left\{\begin{array}{l}0.07 \\
0.07\end{array}\right.$ & $\ldots$ & -.. & 0.13 & 0.19 & - - & -.. & -.. & -.. & -.. & 0.62 & -.-- \\
\hline & & & 500 & & & 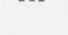 & ( (.03) & $\cdots$ & $\cdots$ & $(.02)$ & $(.08)$ & -.. & -- & -.. & -.. &.- & (.35) & -... \\
\hline 13 & 1.1 & -.. & $\left\{\begin{array}{l}0.09 \\
(08)\end{array}\right.$ & $\cdots$ & $\cdots$ & $\cdots$ & 0.10 & $\cdots$ & $-\cdot$ & -- & 0.20 & $\cdots$ & $-\cdot$ & $\cdots$ & -- & -- & 0.47 & -..- \\
\hline & & & & -.. & -.. & $\cdots$ & {$\left[\begin{array}{l}(.00) \\
0.09\end{array}\right.$} & 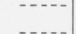 & $\cdots$ & 0.14 & $\begin{array}{l}(.09) \\
0.19\end{array}$ & $\cdots$ & $\cdots$ & $\cdots$ & $\cdots$ & -- & $\begin{array}{l}(.20) \\
0.36\end{array}$ & -... \\
\hline 14 & 1.2 & $\cdots$ & $\cdots$ & -.. & $\cdots$ &.- & $\left\{\begin{array}{l}(.05) \\
\text {. }\end{array}\right.$ & ...... & -... & $(.03)$ & $(.08)$ & $\ldots$ & $\ldots$ & -.. & - & $\ldots$ & $\begin{array}{l}(.09) \\
(.09)\end{array}$ & - \\
\hline 15 & 16 & & & & & & & & 0.10 & $\ldots$ & 0.18 & $\ldots$ & -.. & -.. & 0.17 & 0.32 & 0.37 & .... \\
\hline 10 & 1.0 & $\cdots$ & $\cdots$ & $\cdots$ & -... & $\cdots$ & ... & $\cdots$ & $(.03)$ & $\ldots$ & $(.07)$ & -.. & ... & $\ldots$ & $(-.02)$ & $(.09)$ & $(.10)$ & -... \\
\hline 19 & 2. 3 & ... & -.. & -.. & -.. & -.. & $\left\{\begin{array}{l}0.11 \\
\{07)\end{array}\right.$ & -.. & $\cdots$ & -.. & 0.24 & -.. & --- & 0.48 & 0.24 & 0.32 & 0.72 & .... \\
\hline & & . & 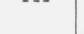 & 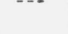 & 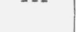 & 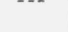 & [(.07) & $\cdots$ & -- & $-\cdots$ & $(.13)$ & -- & -.. & $(.30)$ & $(.05)$ & $(.09)$ & $(.45)$ & -..- \\
\hline \multicolumn{19}{|c|}{ SERIES B-REGULARLY HYDRATED DOLOMITIC LIMES } \\
\hline 22 & 16.1 & $\{6.8$ & --- & $\ldots$ &.- & -- & -.. & 8.0 & ... & -.- & 8.8 & -- & -.. & -.. & -.. & -.. & -- & 9.4 \\
\hline & & 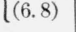 & --- &.-- &.-- & -.. &.-- & $(7.9)$ & ... & $\ldots$ & $(8.7)$ & ... & ..- & -.. & ... & -.. & -.. & $(9.1)$ \\
\hline 32 & 26.8 & $\ldots$ & $\left\{\begin{array}{c}13.0 \\
(12.0)\end{array}\right.$ & $-\cdot$ & $--\cdot$ & -.. & -.. & 10.6 & -.. & $\cdots$ & 12.0 & $-\cdot$ & -.. & -- & -- & $-\cdot$ & -- & 11.9 \\
\hline & & 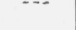 & $\{(13.0)$ & ... & -.. & $\ldots$ & -.- & $(10.5)$ & $\ldots$ & $\ldots$ & $(11.9)$ & $\ldots$ & -.. &.- & ... & $\ldots$ & $\ldots$ & $(11.6)$ \\
\hline 35 & 27.7 & -.. & $\left\{\begin{array}{c}15.1 \\
0.5\end{array}\right.$ & -.. & -.- & -.. & ... & 16.3 & ... & ... & 16.5 &.-- & -.. & -.. & -.. & -.. &.- & 16.4 \\
\hline סנ & 21.1 & 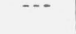 & $\{(15.1)$ & -.. & $\ldots$ & -.. & ... & $(16.2)$ & $\ldots$ & ... & (16.4) & -- & -.. &.- & $\ldots$ & -.. & -.. & (16.1) \\
\hline 37 & 29.3 & ... & $\left\{\begin{array}{c}5.7 \\
-.7\end{array}\right.$ & ..- & 5.9 & 7.6 & -.- & -.- & -.. & ... & 7.3 & 7.1 &..- & -.. & -.. & -.. & -.- & -..- \\
\hline & & 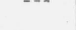 & $\lfloor(5.7)$ & -.. & $(5.9)$ & $(7.6)$ & -.- & $\cdots$ & -.. & ... & $(7.2)$ & $(7.0)$ & -.. & ... & ... & $\ldots$ & ..- & -..- \\
\hline
\end{tabular}


TABLE 5. Effect of varying the cement on the expansion of cement-lime bars prepared in the proportion of 1 cement:1 lime (by weight), and autoclaved at a steam-gage pressure of $295 \mathrm{lb} / \mathrm{in} .^{2}$ for $3 \mathrm{hr}$-Continued

[The expansions of the 17 cements without the addition of limes ranged from 0.0 to 0.30 percent and are shown in brackets. The percentage of expansion obtained after subtracting the percentage of expansion of the cement from the percentage of expansion of the cement-lime bar is given in parenthesis]

\begin{tabular}{|c|c|c|c|c|c|c|c|c|c|c|c|c|c|c|c|c|c|c|}
\hline \multirow{2}{*}{$\begin{array}{l}\text { Lime } \\
\text { num- } \\
\text { ber }\end{array}$} & \multirow{2}{*}{$\begin{array}{l}\text { Unhy- } \\
\text { drated } \\
\text { oxides }\end{array}$} & \multicolumn{17}{|c|}{ Linear expansion of cement-lime bars prepared with cements 1 to 17 , inclusive } \\
\hline & & {$\left[\begin{array}{c}1 \\
{[0.00]}\end{array}\right.$} & $\begin{array}{c}2 \\
{[0.01]}\end{array}$ & $\begin{array}{c}3 \\
{[0.01]}\end{array}$ & $\begin{array}{c}4 \\
{[0.02]}\end{array}$ & $\begin{array}{c}5 \\
{[0.04]}\end{array}$ & $\left.\begin{array}{c}6 \\
{[0.04}\end{array}\right]$ & {$\left[\begin{array}{c}7 \\
{[0.06]}\end{array}\right.$} & $\begin{array}{c}8 \\
{[0.07]}\end{array}$ & $\begin{array}{c}9 \\
{[0.11]}\end{array}$ & $\begin{array}{c}10 \\
{[0.11]}\end{array}$ & $\begin{array}{c}11 \\
{[0.11]}\end{array}$ & $\begin{array}{c}12 \\
{[0.17}\end{array}$ & $\begin{array}{c}13 \\
{[0.18]}\end{array}$ & $\begin{array}{c}14 \\
{[0.19]}\end{array}$ & $\begin{array}{c}15 \\
{[0.23]}\end{array}$ & $\begin{array}{c}16 \\
{[0.27]}\end{array}$ & $\begin{array}{c}17 \\
{[0.30]}\end{array}$ \\
\hline \multicolumn{19}{|c|}{ SERIES C-HIGHLY HYDRATED DOLOM } \\
\hline & $\%$ & $\%$ & $\%$ & $\%$ & $\%$ & $\%$ & $\%$ & $\%$ & $\%$ & $\%$ & $\%$ & $\%$ & $\%$ & $\%$ & $\%$ & $\%$ & $\%$ & $\%$ \\
\hline 49 & 1.4 & -.. & ... & -.. & -.- & ... &.- & & $\cdots$ & -.. & $\begin{array}{l}0.25 \\
(.14)\end{array}$ & -.. & -.. & -.. & -.. & -.. & 0.51 & .... \\
\hline 53 & 2.6 & & $\{0.21$ & -.. & 0.31 & -.. & -.. & 0.42 & -.. & ... & 1.4 & - & 2.9 & 1.6 & -.. & --. & $\begin{array}{r}(.24) \\
-\end{array}$ & 2.7 \\
\hline 00 & 2.0 & ... & {$[(.21)$} & -.. & $(.29)$ & -.. & $\cdots$ & $(.36)$ & -.- & ... & $(1.3)$ & -.. & $(2.7)$ & $(1.4)$ & -.- & $\ldots$ & - & (2.4) \\
\hline 54 & 2.6 & ... & ... & ... & & ... & $\left\{\begin{array}{l}0.21 \\
(.17)\end{array}\right.$ & -.. & -.. & ... & $\begin{array}{l}0.37 \\
(.26)\end{array}$ & -.. & -.. & $\begin{array}{c}0.57 \\
(.39)\end{array}$ & $\begin{array}{l}0.40 \\
(.21)\end{array}$ & $\begin{array}{c}0.46 \\
(.23)\end{array}$ & $\begin{array}{l}0.69 \\
(.42)\end{array}$ & ... \\
\hline 56 & 2.9 & -. & -.. & -.. & -. & ... & ... & & $\left\{\begin{array}{l}0.20 \\
(13)\end{array}\right.$ & -.. & 0.33 & - &.- & 0.85 & - & 0.40 & ( & - \\
\hline 57 & 29 & $\{0.25$ & ... & ... & ... & $\cdots$ & -.. & 0.23 & $\begin{array}{c}(1.13) \\
\ldots\end{array}$ & -.. & $\begin{array}{l}(.22) \\
0.37\end{array}$ & -.. & -.. & $\begin{array}{c}(.67) \\
-\ldots\end{array}$ & $\cdots$ & $\begin{array}{l}(.17) \\
-\ldots\end{array}$ & $\cdots$ & 0.57 \\
\hline $5 r$ & 2.9 & $\{(.25)$ & ... & -.. & ... & -.. & ... & $(.17)$ & -.. & --. & $(.26)$ & -.. & -.. & $\ldots$ & -.. & -.. & - & $(.27)$ \\
\hline 59 & 3.0 & ... & ... & ... & ... & -.. & $\left\{\begin{array}{l}0.22 \\
(.18)\end{array}\right.$ & -.. & -.. & $\begin{array}{l}0.26 \\
(.15)\end{array}$ & $\begin{array}{l}0.37 \\
(.26)\end{array}$ & -.. & -.. & -.. & ... & -.. & $\begin{array}{c}0.62 \\
(.35)\end{array}$ & -... \\
\hline 60 & 3.2 & ... & ... & $\left\{\begin{array}{c}0.22 \\
0.21\end{array}\right.$ & ... & 0.21 & $\ldots$ & -.- & ... & ... & 0.36 & -. & -.. & -.. & ... & ... & 0.73 & ... \\
\hline & & & $\int 0.19$ & {$[0.21)$} & ... & $\begin{array}{l}(.17) \\
-.-\end{array}$ & $\ldots$ & 0.19 & $\ldots$ & ... & $\begin{array}{l}(.25) \\
0.32\end{array}$ & $\cdots$ & -.. & $\cdots$ & $\cdots$ & -.. & (.46) & 0.47 \\
\hline 61 & 3.2 & -.. & $\{(.18)$ & -... & $\cdots$ & ... & ... & (.13) & -.. & ... & $(.21)$ & ... & -.. & ... & -.. & & 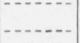 & (. 17) \\
\hline 65 & 4,0 & ... & ... & $\cdots$ & $\left\{\begin{array}{l}0.16 \\
(.14)\end{array}\right.$ & -.. & $\ldots$ & -.. & -.. & $\ldots$ & $\begin{array}{l}0.32 \\
(.21)\end{array}$ & -.. & $\ldots$ &.-- & $\begin{array}{c}0.32 \\
(.13)\end{array}$ & $\begin{array}{l}0.36 \\
(.13)\end{array}$ & $\begin{array}{l}0.51 \\
(.24)\end{array}$ & $\ldots$ \\
\hline 67 & 5. 2 & $\{1.8$ & 0.45 & 2.4 & ... & 1.8 & ... & 1.3 & ... & ... & 3.2 & 2.3 & 2.6 & -.. & $\ldots$ & $\ldots$ & ( & 2.9 \\
\hline & & $\{(1.8)$ & $(.44)$ & $(2.4)$ & -. & $(1.8)$ & -.. & (1.2) & ... & ... & $(3.1)$ & $(2.2)$ & $(2.5)$ & -.. & $\ldots$ & $\ldots$ & ....... & (2.6) \\
\hline 73 & 9.0 & ... & $\left\{\begin{array}{l}1.9 \\
.1\end{array}\right.$ & 4. 7 & -.. & -.. & -.. & ... & -.. & ... & 5.3 & ... & 5.5 & ... & $\cdots$ & -.. & - & 6.1 \\
\hline & & 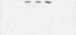 & [(1.9) & $(4.6)$ & -.. & $\cdots$ & -. & $\cdots$ & $\cdots$ & -.. & $(5.2)$ & -.- & $(5.3)$ & $\cdots$ & -.. & -.. & $-\ldots$ & $(5.8)$ \\
\hline 74 & 11.6 & $\ldots$ & $\left\{\begin{array}{c}0.69 \\
08\end{array}\right.$ & $\cdots$ & ... & -.. & $\cdots$ & -. & --. & -. & 3.0 & -- & 3.5 & $-\cdot$ &.- & $\cdots$ & $-\cdots$ & 4.1 \\
\hline & & & {$[(.68)$} & $\cdots$ & $\cdots$ & $\cdots$ & $\cdots$ & -.. & $\cdots$ & $\cdots$ & $(2.9)$ & $\cdots$ & $(3.3)$ & -.. & $\cdots$ & $\cdots$ & $\cdots$ & $(3.8)$ \\
\hline \multicolumn{19}{|c|}{ SERIES D-MAGNESIAN HYDRATED LIMES } \\
\hline 77 & 5.9 & ... & ... & & $\{0.21$ & -. & $\cdots$ & ... & 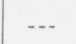 & 0.33 & 0.55 & ... & -.. & $-\cdots$ & $\cdots$ & 0.95 & ... & ...- \\
\hline & & & 0.26 & & & ... & ... & $\cdots$ & $\cdots$ & $(.22)$ & $(.44)$ & $\cdots$ & - & -.. & $\cdots$ & $(.72)$ & ... & - \\
\hline 78 & 7.2 & $\left\{\begin{array}{l}(.26) \\
\text {. }\end{array}\right.$ & $(.25)$ & $\ldots$ & $\begin{array}{l}0.24 \\
(.22)\end{array}$ & $\cdots$ & $\cdots$ & $\begin{array}{l}0.31 \\
(.25)\end{array}$ & $\ldots$ & $\ldots$ & $\begin{array}{l}0.40 \\
(.29)\end{array}$ & $\cdots$ & $\begin{array}{l}0.44 \\
(.27)\end{array}$ & $\ldots$ & $\cdots$ & $\cdots$ & $\cdots$ & $\begin{array}{l}0.58 \\
(.28)\end{array}$ \\
\hline 80 & 12.7 & $\int 0.54$ & ... & -.. & 0.42 & ... & $\ldots$ & 0.53 & ... & -.. & 0.69 & -.. & -.. & 0.68 & -.. & $\ldots$ & -.. & 0.90 \\
\hline 0 & 12.6 & l(.54) & -.. & -.. & $(.40)$ & -.. & -.. & $(.47)$ & $\cdots$ & -.. & $(.58)$ & $\cdots$ & -.. & $(.50)$ & $\cdots$ & $\cdots$ & -.. & $(.60)$ \\
\hline
\end{tabular}


standard method of test for autoclave expansion of portland cement [6]) are given in brackets directly below the numerical listings of the cements. The values for the percentage of expansion of the cement-lime bars are listed in each column. In addition, the percentage of expansion obtained after subtracting the percentage of expansion of the cements from the percentage of expansion of the cement-lime bars is given in parentheses.

The data are insufficient for the application of statistical analysis. Nevertheless, several pertinent observations may be made. Inspection of the expansion values of the cement-lime bars of a particular lime reveals that as the expansion value of the constituent cements increases there is a definite trend for the expansion value of the cement-lime bars to increase also. This indicates that the expansion of the cement used is a factor of moment, and that it is necessary to apply a correction for the expansion contributed by the cement. By the method of trial and error, it can be shown that arbitrarily subtracting the expansion of the neat cement from the total expansion of the cement-lime bar gives the most uniform results for the "net" expansion of a lime. Net expansion values obtained in this manner are shown in parentheses in table 5. Even the net expansion values for a particular lime, however, tend to increase somewhat as the expansion values of the cements increase. For purposes of a test procedure, the variation in net expansion values could be further reduced by eliminating the use of cements of very low or high expansion. For example, good agreement of net expansion values is shown in most instances when the expansion values of the neat cements range between 0.05 and 0.15 percent.

It is realized that the above conclusions are based on limited data and that it would have been desirable to have determined the expansion values of all the limes with all the cements. Unfortunately, this phase of the investigation was the last undertaken, and a more complete study was no longer possible because of the limited quantity of materials remaining.

\section{Behavior of Cement-Lime Specimens During Course of Autoclaving ${ }^{7}$}

(a) Expansion of Specimens During Normal Heating Schedule of Special Autoclave

Figure 12 shows the normal heating schedule of the specially equipped autoclave; the thermal expansion of the parts of the autoclave, including the thermal expansion of the bar; and the expansion of bars prepared with three regularly hydrated dolomitic limes, three highly hydrated dolomitic limes, and one neat portland cement. The thermal expansion reached 0.4 percent at $216^{\circ} \mathrm{C}$ (steamgage pressure of $295 \mathrm{lb} / \mathrm{in}^{2}$ ). Subtracting this value from that recorded for portland cement at $216^{\circ} \mathrm{C}$, or 0.6 percent, gives the value of 0.2 percent for the expansion of the neat portlandcement bar as compared with 0.11 as determined in accordance with the standard method of test for autoclave expansion of portland cement. It is believed that this slight difference in determining percentage of expansion of the cement can in part be ascribed to the method used in determining the percentage of thermal expansion. However, inasmuch as the thermal expansion is insignificant when compared to the expansions of bars prepared with hydrated limes containing appreciable quantities of unhydrated oxide, no further studies were made to determine whether the thermal expansion could be ascertained more accurately.

The curves representing the expansion of the neat portland-cement bar and the cement-lime bars shown in figure 12 involve not only the thermal expansion but also the expansion accompanying the hydration of the constituents of the test specimens. To obtain the expansion other than thermal, one should therefore subtract the percentage of thermal expansion at any specified time from the total percentage of expansion as shown in figure 12 .

The seven curves depicting the expansion characteristics of the cement-lime bars shown in figure 12 were chosen primarily because they were more

\footnotetext{
7 The authors are indebted to G. J. Fink and Emil Trattner for the use of their data on the behavior of cement-lime specimens during the course of autoclaving, previously presented at the Twenty-Eighth Annual Convention of the National Lime Association, Karch 1946.
} 


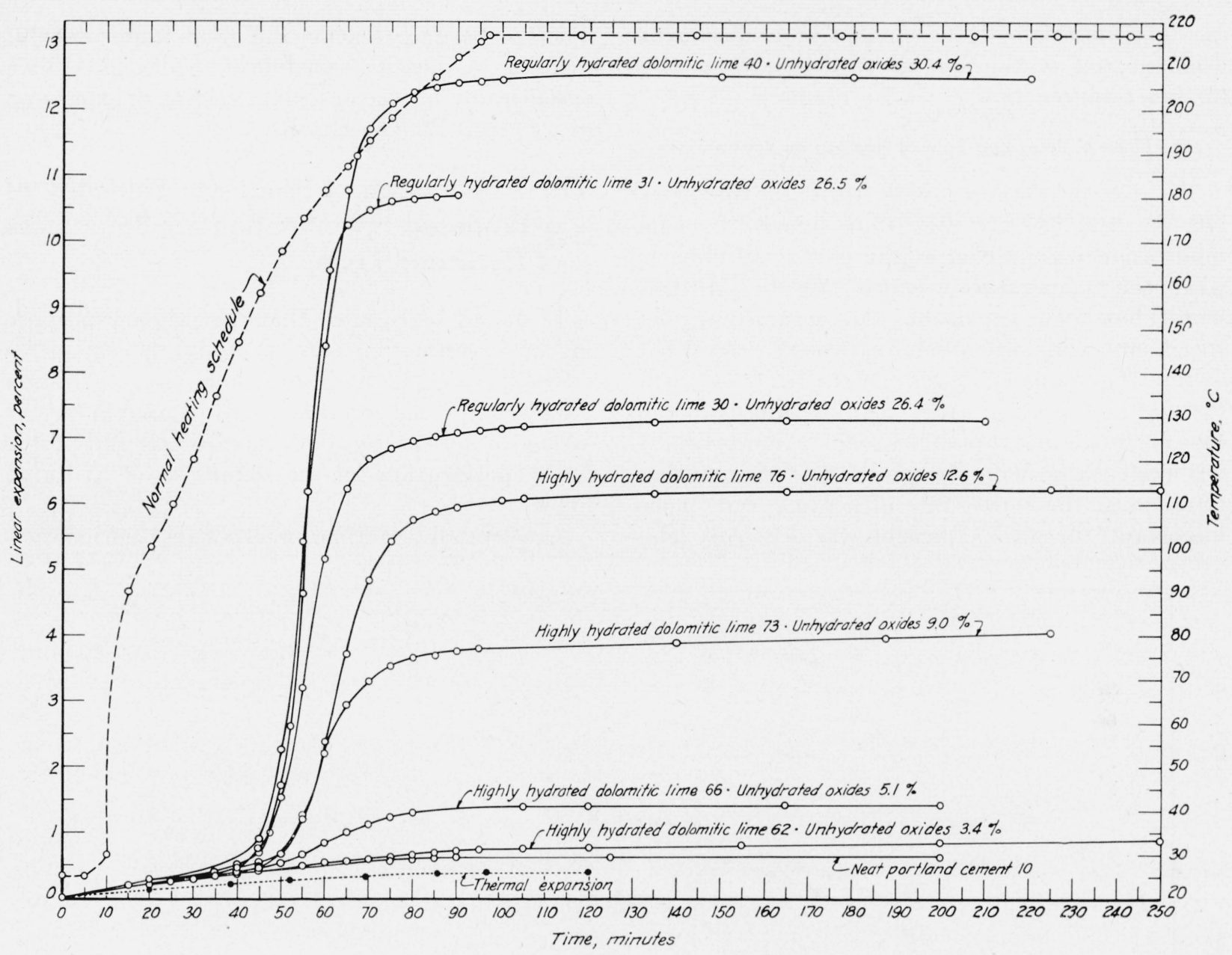

Figure 12. Normal heating schedule of the special autoclave, thermal expansion of the bar and parts of the autoclave, expansion of a neat portland cement bar, and expansions of cement-lime bars prepared with three regularly hydrated and three highly hydrated dolomitic limes in the proportion of $1 C: 1 \mathrm{~L}$.

or less typical of those obtained with other hydrated limes over this range of expansion. No curve showing the expansion of a cement-lime bar prepared with a high-calcium lime is plotted in figure 12 , since such a curve would be obscured because it would very closely coincide with the one plotted for the portland cement. It can be seen from figure 12 that the curves expressing the expansion of the cement-lime test specimens are $\mathrm{S}$-shaped, with a flattening accompanying a decrease in the total expansion. At the normal heating schedule, only a slight amount of the total expansion occurred before the elapse of 45 min, or before a temperature of about $150^{\circ} \mathrm{C}$ was reached. This was followed by a rapid rate of expansion which, in turn, tapered off before a temperature of $216^{\circ} \mathrm{C}$ was reached. Conse- quently, there is little to be gained by continuing the heating at $216^{\circ} \mathrm{C}$ for more than $1 \mathrm{hr}$.

After subtracting the percentage of expansion of the parts of the autoclave at $216^{\circ} \mathrm{C}$ from each of the values of the cement-lime bars at the same temperature and comparing the percentages of expansion thus obtained with those recorded in table 1 for similar 1:1 cement-lime bars, it was found that the expansions obtained with the special autoclave were for the most part appreciably lower than those recorded in table 1 . The most logical explanation for the lower percentage of expansion with the use of the special autoclave appeared to be associated with the lower rate of temperature rise during autoclaving. Consequently, a series of experiments was made of the 
rate of expansion of the cement-lime specimens when heated in the special autoclave at a still further retarded rate.

\section{(b) Effect of Retarding Rate of Heating on Expansion}

The results obtained with three of the limes $(40,73$, and 66$)$ are plotted in figure 13 . The retardation was started at the end of $30 \mathrm{~min}$, or when the temperature reached $120^{\circ} \mathrm{C}$. At this point, but little expansion had occurred in the specimens. The rate of heating was then retarded so that the temperature did not reach $216^{\circ} \mathrm{C}$ until the end of $175 \mathrm{~min}$, rather than $97 \mathrm{~min}$ as in the case of the normal rate of heating. From figure 13 it is evident that not only was the rate of expansion retarded at the slower rate of heating, but, more important, the total expansion was decidedly less.
These experiments show the great importance of defining the heating schedule of an autoclave, by a specification for the autoclave testing of expansion of a cement-lime specimen.

\section{Application of Results to Selection of a Proposed Specification for Soundness of Hydrated Lime}

It should be recalled that the primary purpose of the investigation was to study the expansive characteristics of hydrated limes and to obtain data and information that might be used in formulating an accelerated performance test acceptable for a specification for the soundness of hydrated limes.

Accelerated performance tests have been incorpo-

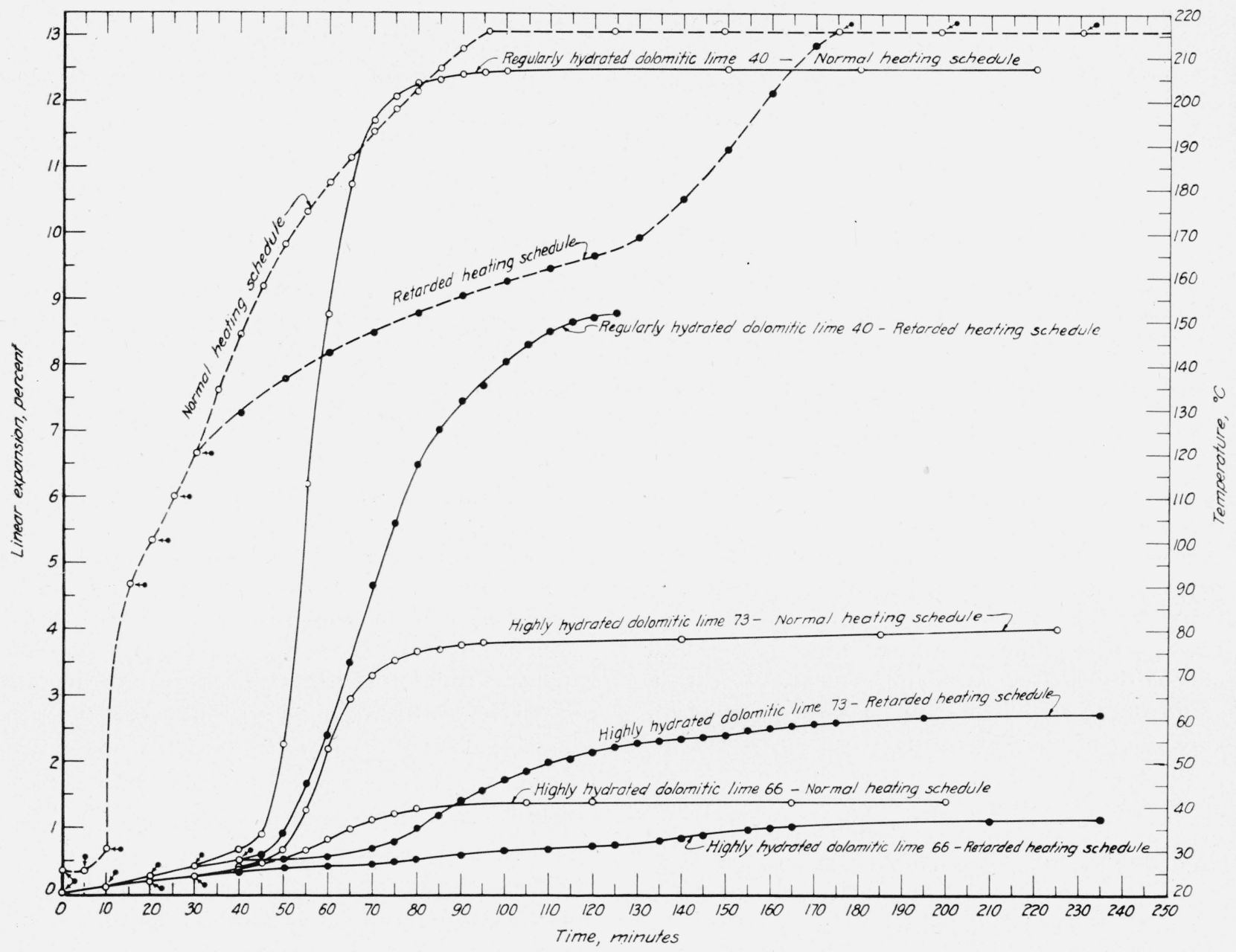

Figure 13. Effect of decreasing the rate of heating the special autoclave to $216^{\circ} C$ (equivalent to gage-pressure of $\left.295 \mathrm{lb} / \mathrm{in.}^{2}\right)$ on the rate of expansion and total expansion of cement-lime bars prepared with three hydrated limes. 
rated into many specifications for the selection of various materials. The need of a test that both accelerates and amplifies the potential expansion of a hydrated lime in service is apparent from considerations of a typical plaster failure involving expansion. Figure 14 shows a marked failure that occurred in white coat along the side of a concrete beam when the expansion of this coat became excessive. Chemical and thermal analyses indicated that the white coat had been prepared from a mixture of gypsum gaging plaster and a normally hydrated dolomitic finishing lime that had contained considerable unhydrated $\mathrm{MgO}$. The slow hydration of the $\mathrm{MgO}$ in the set and hardened white coat to $\mathrm{Mg}(\mathrm{OH})_{2}$ had resulted in a cumulative expansion of such a magnitude that the white coat had sheared away from the underlying base coat of gypsum bond plaster that had been applied to the concrete beam. Calculations based on measurements of the bulge in the white coat revealed that a linear expansion as low as 0.5 percent appears to account for a separation of the magnitude shown in figure 14. The fact that such

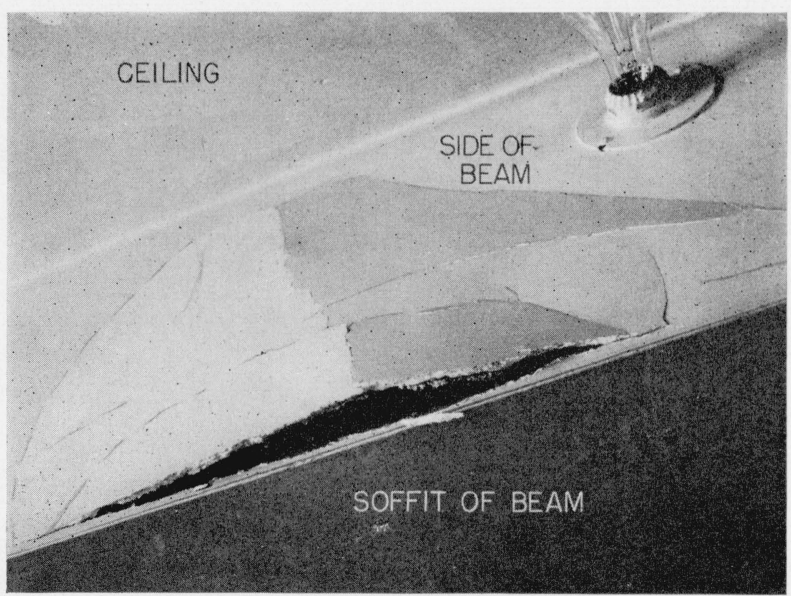

Figure 14. Plaster failure involving the expansion of about 0.5 percent in the white coat along the side of a concrete beam.

failures usually do not take place until some 5 to $10 \mathrm{yr}$ (or longer) after a building has been erected shows the necessity of an accelerated test for judging the soundness of hydrated lime, provided a performance test is to be used. Also, the fact that only a very small expansion can be tolerated within a set and hardened plaster or mortar without causing trouble shows the desirability of amplification of the potential expansion of the constituents composing the plaster or mortar. There is no valid reason for not accepting an accelerated test procedure that amplifies expansion provided it clearly differentiates hydrated limes having low potential expansions from all others. In fact, amplification has a definite advantage in that it facilitates this differentiation.

The factors to be considered in the selection of a method best suited for an accelerated performance test, and the selection of a plausible limit to the percentage of expansion will now be discussed. However, it is not the purpose at this time to write a detailed specification.

\section{Selection of Method}

The selection of a test procedure for a specification for soundness of hydrated lime should be based on several criteria. Among the most important of these are the following:

1. The test should clearly differentiate the hydrated limes having low potential expansions from all others.

2. The procedure should be reproducible.

3. It should not be necessary to repeat the test too often because of such factors as frequent breakage of weak test specimens in handling.

4. The time required to complete the test should be as short as feasible.

5. The procedure, if possible, should be adaptable to apparatus already available in numerous testing laboratories.

On the basis of these criteria, autoclave testing at a steam-gage pressure of $25 \mathrm{lb} / \mathrm{in}^{2}{ }^{2}$ would be eliminated by criterion 4 , because at this pressure ultimate expansion of cement-lime bars is not attained even after $7 \mathrm{hr}$ of autoclaving (fig. 5). On the other hand, the time period required for autoclaving at $295 \mathrm{lb} / \mathrm{in}^{2}{ }^{2}$ is much shorter, actually slightly over $3 \mathrm{hr}$, for the entire procedure of autoclaving, divided as follows: Time of raising pressure to $295 \mathrm{lb} / \mathrm{in}^{2}$, from 1 to $1 \frac{1 / 4}{\mathrm{hr}}$; time of continued heating at this pressure, $1 \mathrm{hr}$ (see fig. 12); and time of cooling autoclave, $1 \mathrm{hr}$. Furthermore, autoclaving at $295 \mathrm{lb} / \mathrm{in}^{2}{ }^{2}$ seems particularly desirable, because numerous testing and research laboratories throughout the country are equipped with autoclaves so designed that the gage pressure can be raised to $295 \mathrm{lb} / \mathrm{in} .^{2}$ within 1 to $1 \frac{1}{4} \mathrm{hr}$ and automatically maintained thereafter at this pressure. Autoclaving at $295 \mathrm{lb} /$ in. $^{2}$, therefore, meets both criteria 4 and 5 . 
Although a test procedure very likely could be devised for autoclaving cement-lime specimens at some gage pressure between 25 and $295 \mathrm{lb} / \mathrm{in}^{2}$, it is doubtful if autoclaving at an intermediate pressure would have any advantages over autoclaving at $295 \mathrm{lb} / \mathrm{in}^{2}$.

The next factor to be discussed is the selection of that ratio of cement to lime in the test specimen that gives the best indication of the potential expansion of hydrated limes. All three ratios $(2 \mathrm{C}: 1 \mathrm{~L}, 1 \mathrm{C}: 1 \mathrm{~L}$, and $1 \mathrm{C}: 2 \mathrm{~L})$ could be used to differentiate the regularly hydrated dolomitic limes, characterized by having the highest percentages of unhydrated oxides and the highest percentages of expansion, from the remaining hydrated limes (figs. 7, 8, and 9). There are, however, certain of the highly hydrated dolomitic limes that apparently have appreciable potential expansions when tested in the proportions of $1 \mathrm{C}: 1 \mathrm{~L}$ or $1 \mathrm{C}: 2 \mathrm{~L}$ that do not clearly show this expansive potentiality when tested in the proportion of $2 \mathrm{C}: 1 \mathrm{~L}$ (fig. 10). With a $2 \mathrm{C}: 1 \mathrm{~L}$ proportion, the percentages of expansion of all the highly hydrated dolomitic limes are distributed rather uniformly over a narrow range-with but one exception, from 0.18 to 0.88 percent. Therefore, a $2 \mathrm{C}: 1 \mathrm{~L}$ proportion does not meet criterion 1 .

In the $1 \mathrm{C}: 1 \mathrm{~L}$ and $1 \mathrm{C}: 2 \mathrm{~L}$ proportions, the highly hydrated dolomitic limes of low potential expansions are easily differentiated from those of appreciable potential expansion. But, as mentioned previously, $1 \mathrm{C}: 2 \mathrm{~L}$ bars are fragile and difficult to handle without excessive breakage. Therefore, by criterion 3, testing hydrated limes in the $1 \mathrm{C}: 2 \mathrm{~L}$ proportion is eliminated. Consequently, having eliminated the $2 \mathrm{C}: 1 \mathrm{~L}$ and $1 \mathrm{C}: 2 \mathrm{~L}$ proportions, the $1 \mathrm{C}: 1 \mathrm{~L}$ proportion remains the most desirable. Since it has been shown that the procedure of testing the cement-lime bars in the $1 \mathrm{C}: 1 \mathrm{~L}$ proportion is reproducible, criterion 2 is also met. In conclusion, therefore, testing cementlime bars prepared in the proportion of $1 \mathrm{C}: 1 \mathrm{~L}$ and autoclaving at $295 \mathrm{lb} / \mathrm{in}^{2}$ meets all of the criteria set forth for a procedure for determining the soundness of hydrated limes.

\section{Proposed Limit of Percentage of Expansion}

Bearing in mind that the test for soundness should differentiate hydrated limes having low potential expansions from all others, and that "Not a single instance has been found where bulging occurred in a white-coat plaster made with highcalcium lime;"' [2], it would appear logical to limit the percentage of expansion to that shown by the high-calcium limes. If the upper limit is placed at 0.6 percent without subtracting the percentage of expansion of the cement, then all of the highcalcium limes would be included and 16 of the highly hydrated dolomitic limes; but at the same time those highly hydrated dolomitic limes that showed moderately high potential expansion would be eliminated. The limit of 0.6 percent may be too restrictive in view of the fact that certain cements might be used that give slightly higher expansion than cement 10, which was used in the bulk of the experiments in the present investigation. It is proposed, therefore, that the upper limit of the linear expansion for a test for soundness be placed at 1.0 percent after subtracting the percentage of expansion of the cement.

It is further proposed that portland cement meeting the requirements of Federal Specification SS-C-192 (type I) for portland cement (ASTM Designation: C 150-46) be used in preparing the $1 \mathrm{C}: 1 \mathrm{~L}$ test bars, and in addition that only those cements having expansions ranging from 0.05 to 0.15 be selected.

A limit of 1.0 percent should afford adequate protection for the consumer and not work an undue hardship on the producer. All high-calcium hydrated limes and quicklimes, if properly slaked so that the unhydrated oxide is reduced to a low percentage, will easily meet the requirement; and apparently if the highly hydrated dolomitic limes have been hydrated to the extent that the unhydrated oxide is reduced to less than 5 percent, such products should also meet the requirement. The 16 highly hydrated dolomitic limes that meet this requirement were all commercially produced. The remaining 12 do not represent a true crosssection of this type of lime as now being produced. Six, as stated previously, were experimental limes, and the process of manufacture of several of the others has been modified, so that there is good reason to believe that the percentages of unhydrated oxide and the expansions are now of the order of magnitude of the high-calcium limes.

All of the four magnesian limes with the percentage of unhydrated oxide ranging from 5.9 to 12.7 would meet the 1 -percent limit on expansion. Two of these, namely, limes 79 and 80 , with 9.8 and 12.7 percent of unhydrated oxide, respectively, 
would not, however, meet a composition requirement that the quantity of unhydrated oxide shall not exceed 8 percent by weight on the as-received basis $[3,4]$.

On the other hand, it is obvious that certain of the highly hydrated dolomitic limes having quantities of unhydrated oxide as low as 8 percent can, nevertheless, exhibit appreciable autoclave expansion. In either case, since an accelerated performance test should be preferable to a limitation of the chemical composition, it is believed that a limit of 1 percent on the expansion of $1 \mathrm{C}: 1 \mathrm{~L}$ bars is better than the 8-percent limit on the unhydrated oxides.

\section{Summary}

An investigation of the expansive characteristics of hydrated limes was completed, and from the data obtained an accelerated performance test was proposed for testing the soundness of hydrated lime.

Samples of 80 structural hydrated limes, representative of the production in the United States, were classified on the basis of chemical analyses and calculated unhydrated oxide content as high-calcium, regularly hydrated dolomitic, highly hydrated dolomitic, and magnesian limes. The percentage of unhydrated oxide for the highcalcium class ranged from 0 to 3.9 ; for the regularly hydrated dolomitic from 16.1 to 34.3 ; for the highly hydrated dolomitic from 1.4 to 12.6 ; and for the magnesian from 5.9 to 12.7.

On the basis of preliminary experiments, portland cement was selected as the most suitable hydraulic material for gaging hydrated lime in the preparation of test specimens suitable for autoclaving. A technique for preparing, curing, and autoclaving 1 - by 1 - by 10 -in. cement-lime bars was developed. The method for determining the linear expansion of cement-lime bars prepared in the proportion of 1 cement to 1 lime, by weight, and subsequently autoclaved at $295 \mathrm{lb} / \mathrm{in}^{2}$ for $3 \mathrm{hr}$ was found to be reproducible by three independent operators.

Data on the expansions of cement-lime bars prepared in proportions of 2 parts cement to 1 part lime, 1 part cement to 1 part lime, and 1 part cement to 2 parts lime, by weight, and autoclaved to $295 \mathrm{lb} /$ in. $^{2}$ gage pressure for $3 \mathrm{hr}$, showed that bars prepared with the regularly hydrated dolomitic limes, which had the highest percentages of unhydrated oxide, had the highest percentage of expansion. The high-calcium limes, characterized, in general, by the lowest percentages of unhydrated oxide, gave the lowest percentage of expansion. Most of the highly hydrated dolomitic limes had percentages of unhydrated oxide and expansions that were comparable to those of the high-calcium limes. The remainder had percentages of unhydrated oxide and expansions that were greater than those of the highcalcium limes. The four magnesian limes exhibited unique behavior in that each showed lower percentage of expansion than other limes with comparable percentages of unhydrated oxide.

An increase in the proportion of lime in the cement-lime bars was attended by an increase in expansion and by better differentiation between the classes within a series. Bars of the 1 part cement to 2 parts lime series, however, were very weak and were eliminated from consideration for a routine test method.

The effect of 17 different portland cements on the expansion of cement-lime (1:1 by weight) bars was investigated. The neat cements ranged in expansion from 0.00 to 0.30 percent, and they were tested in part with 30 selected limes. The expansion values of cement-lime bars for a particular lime tended to increase as the expansion value of the constituent cement increased. Arbitrarily subtracting the expansion of the neat cement from the total expansion of the cementlime bar gave the most uniform results for the net expansion of the lime.

An autoclave was specially modified for ascertaining the behavior of cement-lime specimens during the course of autoclaving. The results showed that only a slight amount of the total expansion of cement-lime bars occurred before a temperature of $150^{\circ} \mathrm{C}$ was reached. Above $150^{\circ} \mathrm{C}$, a rapid expansion rate was noted, which, in turn, tapered off before a temperature of $216^{\circ}$ $\mathrm{C}$ was reached. Since little expansion occurred after the specimen bad reached the limiting temperature of $216^{\circ} \mathrm{C}$ (equivalent to $295 \mathrm{lb} / \mathrm{in} .^{2}$, steam-gage pressure), it was concluded that continued heating at $216^{\circ} \mathrm{C}$ beyond $1 \mathrm{hr}$ is unnecessary for a test procedure. The results also indicated the importance of a controlled rate of heating the autoclave to $216^{\circ} \mathrm{C}$, as a decreased rate of heating gave decreased expansions.

It was proposed that hydrated limes be tested 
$\mathrm{n}$ the proportion of 1 cement: 1 lime (by weight), that the cement used have an expansion between 0.05 and 0.15 percent, that the autoclaving be done at $295 \mathrm{lb} / \mathrm{in}^{2}$ gage pressure for $1 \mathrm{hr}$ according to a controlled schedule and, finally, that the expansion obtained after subtracting the percentage of expansion of the neat cement bar from the total expansion of the cement-lime bar be limited to not more than 1 percent.

The authors express thanks and appreciation to Emil Trattner and G. J. Fink, former Research Associates at the National Bureau of Standards, for obtaining a great portion of the data on autoclave tests included in this publication.

\section{References}

[1] Lansing S. Wells and Kenneth Taylor, J. Research NBS 19, 215 (1937) RP1022.

[2] E. S. Newman, Bul. Am. Ceram. Soc. 26, No. 4, 117 (1947).

[3] Proposed amendment to Federal Specification SS-L351 for lime; hydrated (for) structural purposes. Date of amendment, Feb. 2, 1940.

[4] Tentative specifications for special finishing hydrated lime. ASTM Designation: C206-46T. ASTM Standards, part II, 1306 (1946); and Tentative specifications for hydrated lime for masonry purposes. ASTM Designation: C207-46T (Type S-Special hydrated lime for masonry purpose) ASTM Standards, part II, 1308 (1946).
[5] Standard specifications for gypsum plastering including requirements for lathing and furring. American Standards Assn. A. 42.1-1946, J. W. McBurney, Ind. Stand. 18, No. 4, 79 (1947).

[6] Standard method of test for autoclave expansion of portland cement ASTM Designation: C151-43, ASTM Standards, part II, 14 (1946); also American Association State Highway Officials Standard AASHO No. T 107-45; as well as Federal Specification SS-C-158b for cements, hydraulic, general specifications (methods for sampling, inspection, and testing).

[7] Federal Specification SS-L-351 for lime; hydrated (for) structural purposes.

[8] Tentative revision of standard methods of chemical analysis of limestone, quicklime, and hydrated lime. ASTM Designation: C25-44 submitted June, 1945, see ASTM Standards, part II, 1701 (1946).

[9] G. J. Fink and Emil Trattner, Proc. ASTM 45, 723 (1945).

[10] Federal Specification SS-C-192 for cements: portland. See also Type I Cement of Standard Specifications for portland cement ASTM Designation: C150-46, ASTM Standards, part II, 1 (1946).

[11] Federal Specification SS-C-158b for cements, hydraulic; general specifications (methods for sampling, inspection, and testing) paragraphs $\mathrm{F}-51$, F-51a, and F-51b.

[12] Federal Specification SS-C-181b, for cement, masonry. Also Standard specifications for masonry cement. ASTM Designation: C91-40, A S T Standards, part II, 7 (1946).

[13] G. W. Snedecor, Statistical methods, 4th ed. (The Iowa State College Press, 1946).

Washington, January 23, 1948. 